\title{
A Multivariate GARCH Model with
}

\section{Time-Varying Correlations}

\author{
Y.K. Tse and Albert K.C. Tsui \\ Department of Economics \\ National University of Singapore
}

December 1998

\begin{abstract}
A bstract: In this paper we propose a new multivariate GARCH model with timevarying correlations. We adopt the vech representation based on the conditional variances and the conditional correlations. W hile each conditional-variance term is assumed to follow a univariate GARCH formulation, the conditional-correlation matrix is postulated to follow an autoregressive moving average type of analogue. By imposing some suitable restrictions on the conditional-correlation-matrix equation, we manage to construct a M GARCH model in which the conditional-correlation matrix is guaranteed to be positive de ${ }^{-}$nite during the optimisation. Thus, our new model retains the intuition and interpretation of the univariate GARCH model and yet satis ${ }^{-}$es the positive-de- nite condition as found in the constant-correlation and BEKK models. We report some $M$ onte Carlo results on the - nite-sample distributions of the QMLE of the varying-correlation MGARCH model. The new model is applied to some real data sets. It is found that extending the constant-correlation model to allow for time-varying correlations provides some interesting time histories that are not available in a constant-correlation model.
\end{abstract}

Key Words: BEKK model, constant correlation, Monte Carlo method, multivariate GARCH model, quasi maximum likelihood estimate, varying correlation

J EL Classi ${ }^{-}$cation: C12

A cknowledgement: Y.K. T se acknowledges the support by the National University of Singapore A cademic R esearch G rant RP-3981003. The email addresses of the authors are, respectively, ecst seyk@ius. edu. sg and ecsat sui @ius. edu. sg. 


\section{Introduction}

Following the success of the autoregressive conditional heteroscedasticity $(\mathrm{ARCH})$ model and the generalized ARCH (GARCH) model in describing the time-varying variances of economic data in the univariate case many researchers have extended these models to the multivariate dimension. Applications of the multivariate GARCH (MGARCH) models to ${ }^{-}$nancial data have been particularly popular. For example, B ollerslev (1990) studied the changing variance structure of the exchange rate regime in the European M onetary System assuming the correlations to be time invariant. K roner and Claessens (1991) applied the models to calculate the optimal debt portfolio in multiple currencies. Lien and Luo (1994) evaluated the multiperiod hedge ratios of currency futures in a MGARCH framework. Karolyi (1995) examined the international transmission of stock returns and volatility using di ßerent versions of MGARCH models. Baillie and Myers (1991) estimated the optimal hedge ratios for commodity futures and argued that these ratios are nonstationary. Gourieroux (1997, Chapter 6) presented a survey of several versions of MGARCH models. See also Bollerslev, Chou and Kroner (1992) and Bera and Higgins (1993) for surveys on the methodology and applications of GARCH and MGARCH models.

B ollerslev, E ngle and Wooldridge (1988) provided the basic framework for a M GARCH model. They extended the GARCH representation in the univariate case to the vectorized conditional-variance matrix. Their speci ${ }^{-}$cation follows the traditional autoregressive moving average time series analogue. While this so-called vech representation is very general, it involves a large number of parameters. Empirical applications require further restrictions and simpli' cations. A popular member of the vech-representation family is the diagonal form. Under the diagonal form, each variance-covariance term is postulated to follow a GARCH-type equation with the lagged variance-covariance term and the product of the corresponding lagged residuals as the right-hand-side variables 
in the conditional-(co)variance equation.

It is often di \pm cult to verify the condition that the conditional-variance matrix of an estimated MGARCH model is positive de ${ }^{-}$ite. ${ }^{1}$ Furthermore, such conditions are often very di \pm cult to impose during the optimisation of the log-likelihood function. Bollerslev (1990) suggested the constant-correlation MGARCH (CC-MGARCH) model that can overcome these di \pm culties. He pointed out that under the assumption of constant correlations, the maximum likelihood estimate (MLE) of the correlation matrix is equal to the sample correlation matrix. As the sample correlation matrix is always positive de ${ }^{-}$nite, the optimisation will not fail as long as the conditional variances are positive. In addition, when the correlation matrix is concentrated out of the log-likelihood function further simpli ${ }^{-}$cation is achieved in the optimisation.

Due to its computational simplicity, the CC-M GARCH model is very popular among empirical researchers. However, while the constant-correlation assumption provides a convenient MGARCH model for estimation, some studies found that this assumption is not supported by some - nancial data. Bera and Kim (1996) and Tse (1998) found that the stock returns across di ßerent national markets exhibit time-varying correlations. Thus, there is a need to extend the MGARCH models to incorporate time-varying correlations and yet retain the appealing feature of satisfying the positive- de ${ }^{-}$nite condition during the optimisation.

Engle and Kroner (1995) proposed a class of MGARCH model called the BEKK (named after Baba, Engle, $\mathrm{K}$ raft and $\mathrm{K}$ roner) model. The motivation is to ensure the condition of a positive de nite conditional-variance matrix in the process of optimisation. Engle and K roner provided some theoretical analysis of the BEKK model and related it to the vech-representation form. A nother approach examines the conditional variance as a factor model. The works by Diebold and Nerlove (1989), Engel and Rodrigues (1989)

\footnotetext{
${ }^{1}$ Engle, Granger and K raft (1984) presented the necessary conditions for the conditional-variance matrix to be positive de nite in a bivariate $\mathrm{ARCH}$ model. Extensions of these results to more general models are, however, intractable.
} 
and Engle, $\mathrm{Ng}$ and Rothschild (1990) were along this line. One disadvantage of the BEKK and factor models is that the parameters cannot be easily interpreted, and their net e Rects on the future variances and covariances are not readily seen. Bera, Garcia and Roh (1997) reported that the BEKK model does not perform well in the estimation of the optimal hedge ratios. Lien, Tse and T sui (1998) reported di \pm culties in getting convergence when using the BEK K model to estimate the conditional-variance structure of spot and futures prices.

In this paper we propose a new MGARCH model with time-varying correlations. Basically we adopt the vech representation. The variables of interest are, however, the conditional variances and conditional correlations. We assume a vech-diagonal structure in which each conditional-variance term follows a univariate GARCH formulation. The remaining task is to specify the conditional-correlation structure. We apply an autoregressive moving average type of analogue to the conditional-correlation matrix. By imposing some suitable restrictions on the conditional-correlation-matrix equation, we manage to construct a MGARCH model in which the conditional-correlation matrix is guaranteed to be positive de ${ }^{-}$nite during the optimisation. Thus, our new model retains the intuition and interpretation of the univariate GARCH model and yet satis ${ }^{-}$es the positive-de- nite condition as found in the constant-correlation and BEKK models.

The plan of the rest of the paper is as follows. In Section 2 we describe the construction of the varying-correlation MGARCH model. As in other MGARCH models, the new model can be estimated using a quasi-MLE (QMLE) approach. Some Monte Carlo results on the " nite-sample distributions of the QMLE of the varying-correlation MGARCH model are reported in Section 3. Section 4 describes some illustrative examples of the new model using some real data sets. These are the exchange rate data, interest rate data and stock price data. The new model is compared against the CCMGARCH model. It is found that extending the constant-correlation model to allow for time varying correlations provides some interesting empirical results. The estimated 
conditional-correlation path provides an interesting time history that would be lost in a constant-correlation model. Finally, we give some concluding remarks in Section 5.

\section{A Varying-Correlation MGARCH Model}

Consider a multivariate time series of observations $f y_{t} g, t=1 ;: ; ; T$, with $K$ elements each, so that $y_{t}=\left(y_{1 t} ; \ldots ; y_{K t}\right)^{0}$. We assume that the observations are of zero (or known) mean. This assumption simpli ${ }^{-}$es the discussions without straining the notations. ${ }^{2}$

The conditional variance of $y_{t}$ is assumed to follow the time-varying structure given by

$$
\operatorname{Var}\left(y_{t} j \oplus_{t_{i}}\right)=-{ }_{t},
$$

where $\odot_{t}$ is the information set at time t. We denote the variance elements of - $t$ by $3 / 4 \mathrm{t}$, for $\mathrm{i}=1 ; \ldots ; ; \mathrm{K}$, and the covariance elements by $3 / 4 \mathrm{jt}$, where $1 \cdot \mathrm{i}<\mathrm{j} \cdot \mathrm{K}$. Denoting $D_{t}$ as the $K £ K$ diagonal matrix with the ith diagonal element being $3 / 4 t$, we let ${ }^{2}=D_{t}{ }^{1} y_{t}$. Thus, ${ }^{2} t$ is the standardised residual and is assumed to be serially independently distributed with mean zero and variance matrix $i_{t}=f^{1} / 3 \mathrm{f} t \mathrm{~g}$. Of course, $i t$ is also the correlation matrix of $y_{t}$ and $-t=D_{t} i_{t} D_{t}$.

To specify the conditional variance of $y_{t}$, we adopt the vech-diagonal formulation as initiated by Bollerslev, Engle and Wooldridge (1988). Thus, each conditional-variance term follows a univariate $\mathrm{GARCH}(p, q)$ model given by the following equation:

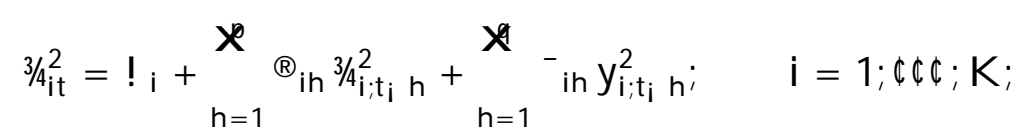

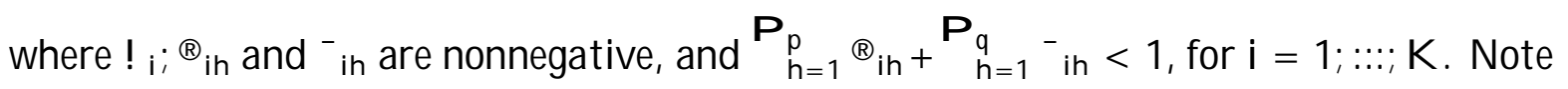
that we may allow $(p, q)$ to vary with i so that $(p, q)$ should be regarded as the generic

\footnotetext{
${ }^{2} \mathrm{~A}$ dditional parameters would be required to represent the conditional-mean equation in the complete model if the mean is unknown. Under certain conditions, the MLE of the parameters in the conditionalmean equation is asymptotically uncorrelated with the MLE of the parameters of the conditionalvariance equation. Under such circumstances, we may treat $y_{t}$ as pre ${ }^{-}$Itered observations (see Bera and Higgins (1993) for further discussions). Otherwise, the parameter vector has to be augmented to take account of the unknown mean.
} 
order of the univariate GARCH process. R esearchers adopting the vech-diagonal form typically assume that the above equation also applies to the conditional-covariance terms in which $3 / 4$ is replaced by $3 / 4 \mathrm{jt}$ and $y_{\mathrm{it}}^{2}$ is replaced by $y_{i t} y_{j t}$ for $1 \cdot \mathrm{i}<\mathrm{j} \cdot \mathrm{K}$. We shall, however, deviate from this approach. Speci- cally, we shall focus on the conditionalcorrelation matrix and adopt an autoregressive moving average analogue on this matrix. Thus, we assume that the time-varying conditional-correlation matrix $\mathrm{i}_{\mathrm{t}}$ is generated from the following recursion:

$$
\mathrm{it}_{\mathrm{t}}=\left(1 ; \mu_{1} \mathrm{i} \mu_{2}\right) \mathrm{i}+\mu_{1} \mathrm{it}_{\mathrm{i}_{1}}+\mu_{2} \underline{\mathrm{a}}_{\mathrm{t}_{\mathrm{i}}} \text {; }
$$

where $\mathrm{i}=\mathrm{f}^{1 / \mathrm{p}} \mathrm{g}$ is a (time-invariant) $\mathrm{K} f \mathrm{~K}$ positive de- nite parameter matrix with unit diagonal elements and ${ }^{a} t_{i_{1}}$ is a $\mathrm{K} f \mathrm{~K}$ matrix whose elements are functions of the lagged observations of $y_{t}:{ }^{3}$ The functional form of ${ }^{a} t_{i}$ will be speci- ed below. The parameters $\mu_{1}$ and $\mu_{2}$ are assumed to be nonnegative with the additional constraint that $\mu_{1}+\mu_{2}$. 1. Thus, $i t$ is a weighted average of $i, i_{t_{1}}$ and ${ }^{a} t_{i}$. Hence, if ${ }^{a} t_{i}$ is $a$ well-de- ned correlation matrix (i.e., positive de ${ }^{-}$nite with unit diagonal elements), i t will also be a well-de ${ }^{-}$ned correlation matrix. ${ }^{4}$

It can be observed that ${ }^{a} t_{i} 1$ is analogous to $y_{i ; t_{i}}^{2}$ in the univariate $\operatorname{GARCH}(1,1)$ model. However, as $\mathrm{i}_{\mathrm{t}}$ is a standardised measure, we also require ${ }^{a_{\mathrm{t}_{1}}}$ to depend on the (lagged) standardised residuals ${ }^{2}$. Denoting ${ }^{a}{ }_{t}=f \tilde{A}_{i j t} g$, we propose to consider the following speci- cation for ${ }^{\underline{a}} t_{i}{ }_{1}$ :

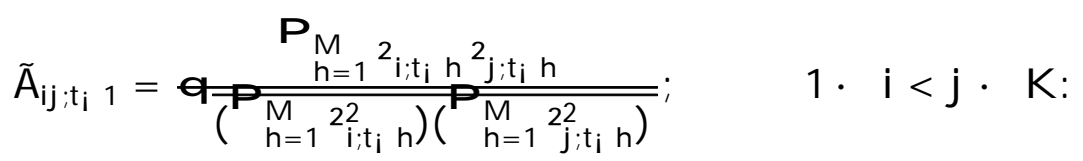

Thus, ${ }^{a}{ }_{t_{i} 1}$ is the sample correlation matrix of $\mathrm{f}^{2}{ }_{t_{i}} ;::: ;{ }^{2}{ }_{t_{i}} \mathrm{~m} g$. We de ${ }^{-}$e $E_{t_{i} 1}$ as the

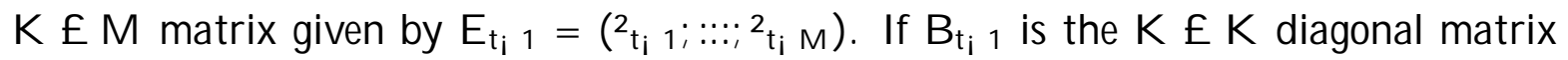

\footnotetext{
${ }^{3}$ For the sake of simplicity and at the risk of being not thorough, we shall describe a correlation matrix as being positive de nite. It is not di \pm cult to see that for some statements made in this section, the term \positive de ${ }^{-}$nite" should, strictly speaking, be replaced by the term \positive semi-de ${ }^{-}$nite" .

${ }^{4} \mathrm{~T}$ his statement is subject to the condition that the recursion starts with a well-de- ned correlation matrix $i_{0}$. Under such conditions, the diagonal elements of $i t$ are unity and $i t$ remains positive de ${ }^{-}$nite.
} 
with the ith diagonal element being $\left({ }_{h=1}^{M_{h}}{ }_{i ; t_{i}}^{22}\right)^{1=2}$ for $i=1 ; \ldots: ; K$, then we have

$$
\underline{a}_{t_{i} 1}=B_{t_{i} 1}^{i 1} E_{t_{i} 1} E_{t_{i} 1}^{0} B_{t_{i} 1}^{i 1}:
$$

Note that when $M=1,{ }^{a} t_{i} 1$ is identically equal to the matrix of unity. Updating the conditional-correlation matrix with respect to the matrix of unity is of course not meaningful. Thus, taking ${ }^{-}$rst-order lag for the formulation of ${ }^{a} t_{i} 1$ is not su \pm cient. Indeed, $M, K$ is a necessary condition for ${ }^{a} t_{i}$ to be positive de ${ }^{-}$nite. When positivede $^{-}$niteness is satis ${ }^{-}$ed, ${ }^{a} t_{i} 1$ is a well-de ${ }^{-}$ned correlation matrix. Thus, the condition $M$, K will be imposed subsequently.

Equation (3) is analogous to the univariate $\mathrm{GARCH}$ equation, with the additional restriction that the sum of the coe \pm cients is equal to 1 . Indeed, i $t$ involves updating the conditional-correlation matrix with respect to the latest conditional-correlation matrix $i_{t_{i}}$ and a sample estimate of the conditional-correlation matrix based on the recent M standardised residuals. We shall call the model speci- ed by (2), (3) and (5) the varying-correlation MGARCH (VC-MGARCH) model.

A ssuming normality, $y_{t} \gg N\left(0 ; D_{t} i_{t} D_{t}\right)$, so that the log-likelihood ' ${ }_{t}$ of the observation $\mathrm{y}_{\mathrm{t}}$ is given by:

$$
\begin{aligned}
& { }_{t}=i \frac{1}{2} \ln j D_{t i t} D_{t} j i \frac{1}{2} y_{t}^{0} D_{t}^{i}{ }^{1}{ }_{t}^{i}{ }^{1} D_{t}^{i}{ }^{1} y_{t}
\end{aligned}
$$

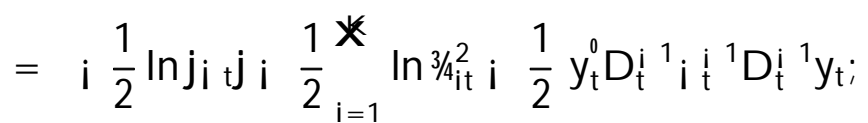

from which we can obtain the log-likelihood function of the sample as ${ }^{`}={ }_{t=1}^{P_{t}}{ }_{t}$ : Hence, the log-likelihood function is conditional on the values i 0 ; $\underline{a}_{0}$ and $y_{0}$ being ${ }^{-}$xed. These assumptions have no eßects on the asymptotic distribution of the QMLE. Denoting

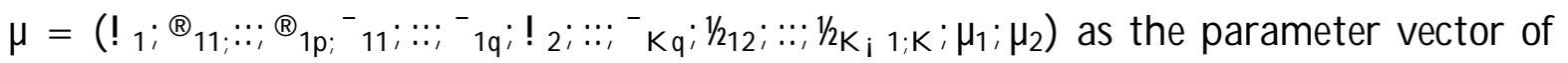
the model, the QMLE of $\mu$ is obtained by maximising ' with respect to $\mu$. We shall denote this value by $\hat{\mu}$ :

For parameter parsimony, $(p, q)$ is usually taken to be of low order. For $p=q=1$, 
the total number of parameters in the VC-MGARCH model is $3 K+K(K+1)=2+2$. In comparison, an unrestricted BEKK model with order 1 for both the lagged conditionalcovariance matrix term and the outer product of the lagged residuals term has $\mathrm{K}(\mathrm{K}+$ 1) $=2+2 K^{2}$ parameters. For example, for $K=2,3$ and 4 , the number of parameters in the VC-MGARCH model is 9, 14 and 20, respectively, while that for the BEKK model is 11, 24 and 42, respectively. The number of parameters in the VC-M GARCH model always exceeds that of the constant-correlation model by 2 , due to the parameters $\mu_{1}$ and $\mu_{2}$. Indeed the CC-MGARCH model is nested within the VC-MGARCH model by imposing the restrictions $\mu_{1}=\mu_{2}=0$ :

The conditions $0 \cdot \mu_{1} ; \mu_{2} \cdot 1$ and $\mu_{1}+\mu_{2} \cdot 1$ pose some problems in the optimisation. One way to get around this di \pm culty is through transformation. For example, we may de $\mathrm{e}^{-}$ne $\mu_{\mathrm{i}}=, 2=\left(1+, 2+, \frac{2}{2}\right)$ for $\mathrm{i}=1 ; 2$; where , 1 and , 2 are unrestricted parameters. The log-likelihood function may be initially optimised with respect to , 1,2 and other parameters of interest. The optimisation is then shifted to the original vector $\mu$ when convergence with respect to $, 1,2,2$ and other parameters has been achieved. This technique is used in the computations reported in this paper.

\section{Some Monte Carlo R esults}

Although the GARCH type of models have been applied extensively in the literature, little has been known about the theoretical asymptotic distribution of the Q MLE of these models. Consistency and asymptotic normality have often been assumed. The works of Weiss (1986) and Lumsdaine (1996) represent few of the studies on the asymptotic distribution of the QMLE in the univariate case. For MGARCH models, theoretical results are even more scanty.

In the univariate case, Engle, Hendry and Trumble (1985), B ollerslev and Wooldridge (1992) and Lumsdaine (1995) examined the small-sample properties of the QMLE of the 
$A R C H$ and GARCH models. In this section we report some results on the small-sample properties of the QM LE of the VC-M GARCH model based on a small-scale M onte Carlo experiment. It is not our intention to provide a comprehensive $M$ onte $\mathrm{C}$ arlo study of the QMLE. We shall focus our interest on the small-sample bias and mean squared error only. The reliability of the inference concerning the model parameters will not be examined. Our results, however, will provide some preliminary evidence with respect to the small-sample properties of the QMLE of the VC-M GARCH model.

We consider bivariate VC-M GARCH models in which the conditional-variance equations are given by:

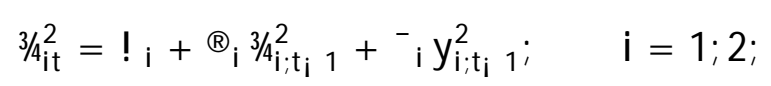

and the conditional correlation coe \pm cient is given by:

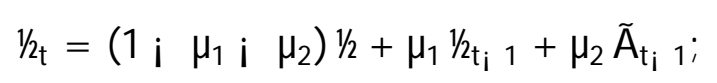

where $\tilde{A}_{t_{i}}$ is given by:

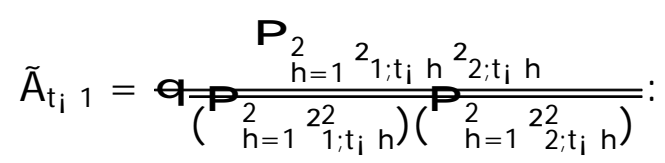

with ${ }^{2}$ it $=y_{\text {it }}=3 / 4 \mathrm{t}$ for $\mathrm{i}=1 ; 2 .{ }^{5}$

We consider four experimental setups. The true parameter values of the data generating processes of these experiments, labelled E1 through E4, are given in Tables 1.1 and 1.2. Observations $f_{\mathrm{t}} \mathrm{g}$ are generated from these models assuming the errors are normally distributed. We consider $\mathrm{T}=500 ; 1000$ and 1500 . The QM LE are calculated for each generated sample. Using M onte Carlo samples of 1000 runs, we estimate the bias and mean squared error (MSE) of the QMLE.

E 1 and E 2 represent models with higher volatility persistence (as measured by $\AA_{+}+$ ${ }_{i}{ }_{i}$ ), while E 3 and E 4 represent models with lower volatility persistence. The selected

\footnotetext{
${ }^{5} \mathrm{~A}$ ll computations reported in this paper assume $\mathrm{M}=\mathrm{K}$ in the de nition of ${ }_{\mathrm{a}}{ }_{\mathrm{t}}$.
} 
values of $1 / 2$ in the experiments vary from 0.2 to 0.7 . It can be seen from Tables 1.1 and 1.2 that the biases of the QMLE are generally quite small. The bias decreases with the sample size, although in some cases not steadily. Likewise, the same is true for the M SE. Overall, the M onte Carlo results suggest that the QMLE is likely to be consistent. For the sample sizes and models considered, the bias and MSE appear to be small.

In the next section, we report the empirical results of applying the VC-MGARCH model to some real data sets.

\section{Some Illustrative Examples}

We examine three sets of ${ }^{-}$nancial data. These are the exchange rate data, interest rate data and stock price data, denoted by DS1, DS2 and DS3, respectively. DS1 consists of two exchange rate (versus US dollar) series, namely, the British Pound (B) and the Deutschmark (D). These series represent daily observations from J anuary 1990 to J une 1998, with 2137 observations. DS2 covers three series of bond yield data, consisting of the yields of the 3-month Treasury Bill (M), the 1-year Treasury Note (O) and the 10-year Treasury B ond (T) in the US. The observations are weekly (Wednesday) " gures from J anuary 1982 through A pril 1998, totalling 850 observations. DS3 covers the stock price indices of three national markets. These are the markets of Hong $\mathrm{K}$ ong $(\mathrm{H})$, J apan (J) and Singapore (S), as measured by the Hang Seng Index, the Nikkei Stock A verage 225 and the SE S-A LL Index, respectively. We sample the data from every ${ }^{-} \mathrm{fth}$ trading day for the period of J anuary 1990 through December 1997, with 340 observations. This sampling method alleviates the problem of nonsynchronous trading days for the three markets. DS1 and DS2 were downloaded from the website of the Federal Reserve Bank of Chicago. DS3 was compiled from various issues of the Stock Exchange of Singapore J ournal.

Figures 1 through 3 present the plots of the eight series in the three data sets. For 
Figure 3, the values of the Hang Seng Index and the Nikkei Stock Average 225 have been scaled down by a factor of one-tenth for the purpose of presentation. We can see that the bond yields moved closely together. In contrast, the stock market indices exhibited periods of divergence. For example, in the early 1990s, the J apan market experienced prolonged period of downturn, while the Hong K ong and Singapore markets were gradually moving upwards. Table 2 provides a summary of the descriptive statistics of the data. The summary statistics refer to those of the di ßerences of the logarithmic series (expressed in percentage). It can be seen that all di ®erenced logarithmic series exhibit negative skewness and excess kurtosis (compared to the normal distribution) in the unconditional distribution. While the exchange rate data demonstrate no evidence of serial correlation, both the interest rate data and the stock return data have signi ${ }^{-}$cant serial correlation as suggested by the $\mathrm{Q}_{1}$ statistics. The $\mathrm{Q}_{2}$ statistics show that there is serial correlation in the conditional variance of all data sets and GARCH type of modelling may be required. In the subsequent analysis, we apply autoregressive ${ }^{-}$Iters to the di ßerenced logarithmic series and model the "Itered residuals using MGARCH models. The autoregressive ${ }^{-1}$ ters are estimated using ordinary least squares (OLS).

We ${ }^{-} t$ the CC-MGARCH model to all data sets using Bollerslev's (1990) algorithm. For DS2 and DS3 we consider trivariate model as well as bivariate (pairwise) models. The results are summarised in Table 3. It can be observed that the estimates of $\AA_{1}{ }^{-}$and $1 / 2$ are all statistically signi ${ }^{-}$cant at the 5 percent level for DS1 and DS2. For DS3, which has the smallest sample size, some estimates of ${ }^{\circledR}$ and - ${ }^{-}$are not statistically signi ${ }^{-}$cant, while all estimates of $1 / 2$ are signi ${ }^{-}$cant. The exchange rate data have the highest intensity of persistence in volatility according to the estimates of ${ }^{B}+^{-}$. Rather interestingly, the estimates of ${ }^{\circledR}+{ }^{-}$are quite robust for each series, regardless of what other series are included in the CC-MGARCH (whether bivariate or trivariate) system. For example, the estimates of ${ }^{B}+^{-}$for the returns in the J apanese market $(\mathrm{J})$ vary from 0.9085 to 0.9194 for three di ßerent systems. 
W ith respect to the correlation coe \pm cients, the returns across di ßerent national markets have the lowest correlation. In no case is the estimated correlation coe \pm cient higher than 0.57 . For the interest rate data, the correlation between the medium-term ( 0 ) and long-term $(T)$ rates has the highest value. As expected, the correlation between the short-term ( $\mathrm{M}$ ) and long-term $(\mathrm{T})$ rates has the lowest value. A gain, it is quite remarkable that the estimated correlation coe \pm cient between each pair of series is quite robust regardless of whether it is an estimate from a bivariate or trivariate system.

Table 4 summarises the estimation results of the VC-M GARCH models for the three data sets. It can be seen that the intensity of the volatility persistence has increased compared to the CC-MGARCH models. For example, for data sets DS2 and DS3, 7 out of 9 estimates of ${ }^{\circledR}+{ }^{-}$are larger than the corresponding estimates in the constantcorrelation models. For DS1 and DS2, the estimates of $1 / 2$ in the varying-correlation models are larger than the corresponding estimates of $1 / 2$ in the constant-correlation model. A lso, for these two data sets the estimates of $1 / 2$ are quite stable irrespective of the system in which this parameter is estimated. For DS3, however, the estimates of $1 / 2$ are no longer stable with respect to the system in which it is estimated. For example, $2 / / 7 S$ is 0.7314 in the bivariate system of $(H, S)$, but is equal to 0.6207 in the trivariate system of $(H, J, S)$. A lso, while $1 / \mathrm{J}_{\mathrm{S}}$ is $0.5691 \mathrm{in}$ the system $(\mathrm{J}, \mathrm{S})$, it drops to 0.3333 in the system $(H, J, S)$.

It can be seen that most estimates of $\mu_{1}$ and $\mu_{2}$ are statistically signi ${ }^{-}$cant at the 5 percent level. The only exceptions are the estimates of $\mu_{2}$ in the system $(M, T)$ in DS2 and in the system $(H, J)$ in DS3. As the CC-MGARCH model is nested within the VC-MGARCH model, ignoring the extension would induce model misspeci ${ }^{-}$cation. We now proceed to examine the model diagnostics for the constant-correlation and varyingcorrelation models.

Table 5 summarises a battery of diagnostic tests for the ${ }^{-}$tted MGARCH models. $Q_{i}(20)$ tests for the autocorrelation in the standardised residuals of series $i$. It is the 
B ox-Pierce statistic based on the autocorrelation coe \pm cients of ${ }_{\text {it }}$ up to order 20 . Likewise, $Q_{i j}(20)$ is the Box-Pierce statistic based on the autocorrelation coe \pm cients of

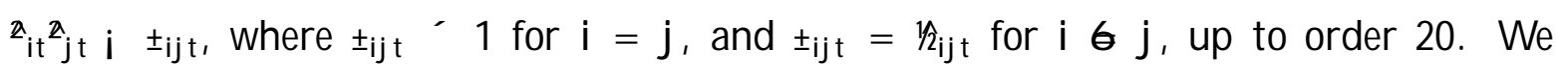
would expect $x_{i t}{ }^{2}{ }_{j t} i \ddagger_{j \mathrm{jt}}$ to be approximately serially uncorrelated if the conditional variance-covariance equations are correct. Thus, $\mathrm{Q}_{\mathrm{ij}}(20)$ can be used to test for inadequacy of the conditional variance-covariance structure. Although the $Q$ statistics are not asymptotically distributed as $\hat{A}^{2}$ (see Li and Mak (1994) and Ling and Li (1997)), the $\hat{A}^{2}$ approximation has nonetheless been used as a rule of thumb for the asymptotic distribution (see, e.g., Bollerslev (1990) Footnote 7). LM C is the Lagrange multiplier test for the assumption of constant correlations in a MGARCH model suggested by Tse (1998). It is asymptotically distributed as a $\hat{A}_{R}^{2}$, where $R=K(K ; 1)=2$, under the null. In Panel $B$ of the table we also present the likelihood ratio statistic $L R$, which tests for the restriction $\mu_{1}=\mu_{2}=0$.

For the CC-MGARCH model of DS1, although LMC cannot detect any violation of the constant-correlation assumption, $\mathrm{Q}_{12}$ suggests the contrary. Otherwise, all other diagnostics do not detect any model misspeci ${ }^{-}$cation. On the other hand, the $\mathrm{Q}_{12}$ statistic of the VC-MGARCH model is insigni ${ }^{-}$cant at the 5 percent level. As expected, the LR statistic is highly signi' cant. Overall, the results suggest the superiority of the VC-MGARCH model over the CC-MGARCH model.

For DS2, the CC-MGARCH model passes most of the diagnostics, except for the LMC statistic of the $(M, T)$ system. For the VC-MGARCH model, all diagnostics cannot detect any misspeci ${ }^{-}$cations. A lthough the LR statistics are signi ${ }^{-}$cant at the 5 percent level, a comparison of Tables 3 and 4 shows that the estimates of the !, ${ }^{\circledR}$ and - do not di ßer much over the two models. Thus, for the interest rate system, not much is lost by imposing constant correlations.

For the stock price data, signi ${ }^{-}$cant time-varying correlation is detected by the LM C statistic in the bivariate system $(H, S)$ as well as the trivariate system. Likewise, the 
LR statistics in these two cases reject the joint hypothesis of $\mu_{1}=\mu_{2}=0$. Otherwise, there is no indication of time-varying correlations in the bivariate systems involving J apan. ${ }^{6}$ Both the CC-MGARCH and VC-MGARCH models pass the various $Q_{i}$ and $\mathrm{Q}_{\mathrm{ij}}$ diagnostics.

Table 6 reports the summary statistics of the in-sample conditional variances, covariances and correlations of the VC-MGARCH(1,1) models. It can be seen that the sample means of the conditional correlations are remarkably close to the QMLE of the correlation coe \pm cients in Table 3. Nonetheless, the range of the conditional correlations can be quite large. For example, for DS1 the range of $\mathrm{f}$ 偌 $\mathrm{Dt} g$ is 0.5884 , with a mean of 0.7001 . For the interest rate data, the ranges of the conditional correlations appear to be smaller. In the trivariate system, the minimum is 0.1777 (for $\mathrm{f} / \mathrm{1} / \mathrm{O} \mathrm{Tg}$ ) and the maximum is 0.2856 (for $f 1 / \mathrm{f}_{\mathrm{H}} \mathrm{Tt} \mathrm{t}$ ). For the data set DS3, we can see that Hong $\mathrm{K}$ ong is the most volatile market, followed by J apan and then Singapore. While the Hong K ong and Singapore markets exhibit higher co-movements, the J apan market appears to have low correlations with Hong K ong and Singapore.

To obtain a clearer picture of the time history of the conditional correlations, we plot the time paths of the conditional correlations based on the bivariate VC-M GARCH $(1,1)$ models. The plots are presented in Figures 4 through 10, in which both the conditional correlations and the QMLE of the CC-MGARCH(1, 1) models (given by the dotted lines) are provided.

From Figure 4 we can see that the conditional correlations of the British Pound and the Deutschmark were quite unstable. Broadly speaking, in the earlier periods of the sample, the conditional correlations were mostly above the estimated value of 0.7168 obtained from the constant-correlation model. After October 1995, however, the conditional correlations dropped below this value. During this period, the British Pound

\footnotetext{
${ }^{6}$ We must note, however, that the lack of statistical signi ${ }^{-}$cance could be due to the small sample size in this data set. Furthermore, the correlations between the J apan market and the Hong Kong and Singapore markets are quite low (see Table 6 below).
} 
was experiencing an upward drift while the Deutschmark was following a downward trend. This time history of the conditional correlations of the two currencies cannot be extracted from the constant-correlation model.

From Figures 5 through 7, we can observe that the conditional correlations of the three bond yields ${ }^{\circ}$ uctuate quite randomly around the values estimated from the constantcorrelation model. This is particularly obvious for the correlations between the 1-year and 10-year yields (i.e., the system $(0, T)$ ). In comparison, the conditional correlations between the 3-month and 1-year rates show slight tendency of dropping in the later period of the sample.

Turning to Figures 8 and 9 , we can see that the path of the conditional correlations between J apan and Singapore appears to be di ßerent from the other combinations. These two markets experienced drop in correlations in the later part of the sample period. Except for a brief period in 1996, the conditional correlations after May 1992 were below the average of 0.3149 estimated from the constant-correlation model. The conditional correlations between the Hong Kong and Singapore markets experienced the most volatile ${ }^{\circ}$ uctuations. The ${ }^{\circ}$ uctuations occurred throughout the sample period and are strong indications of the unstable relationship between the two markets.

We shall end this section by stating that it is not our intention to claim that the VCMGARCH models as presented represent the best MGARCH models for the data. Other MGARCH models could also provide the conditional-correlation structure as presented here. The VC-MGARCH model, however, does provide a viable alternative that is relatively easy to estimate.

\section{Conclusions}

In this paper we propose a new MGARCH model with time-varying correlations. We assume a vech-diagonal structure in which each conditional-variance term follows a 
univariate GARCH formulation. The remaining task is to specify the conditionalcorrelation structure. We apply an autoregressive moving average type of analogue to the conditional-correlation matrix. By imposing some suitable restrictions on the conditional-correlation-matrix equation, we manage to construct a MGARCH model in which the conditional-correlation matrix is guaranteed to be positive de ${ }^{-}$nite during the optimisation.

We report some M onte Carlo results on the " nite-sample distributions of the QMLE of the varying-correlation MGARCH model. It is found that the bias and MSE of the QMLE are small for sample sizes of 500 or above. The new model is applied to three real data sets, namely, exchange rate data, interest rate data and stock price data. The new model is found to pass the model diagnostics satisfactorily, while the constantcorrelation MGARCH model is found to be inadequate in some cases. Extending the constant-correlation model to allow for time-varying correlations provides some interesting empirical results. In particular, the estimated conditional-correlation path provides an interesting time history that would not be available in a constant-correlation model. It is hoped that the varying-correlation M GARCH model would provide a useful alternative for modelling multivariate conditional heteroscedasticity in empirical applications. 


\section{R eferences}

[1] Baillie, R.T . and R.J . Myers, 1991, \Bivariate GARCH Estimation of the Optimal Commodity Futures Hedge", J ournal of A pplied Econometrics, 6, $109\{124$.

[2] B era, A.K., P. Garcia and J S. R oh, 1997, \Estimation of Time-Varying Hedging Ratios for Corn and Soybeans: BGARCH and Random Coe \pm cient Approaches", Working Paper \# 97-06, Urbana: $0 \pm$ ce for Futures and Options Research, University of Illinois at Urbana-Champaign.

[3] B era, A.K. and M.L. Higgins, 1993, \ARCH Models: Properties, Estimation and Testing", J ournal of Economic Survey, 7, $305\{366$.

[4] Bera, A.K. and S. Kim, 1996, ITesting Constancy of Correlation with an Application to International Equity R eturns", mimeo, Center for International B usiness Education and Research (CIBER) Working Paper 96-107, University of Illinois, Urbana-Champaign.

[5] Bollerslev, T., 1990, \M odelling the Coherence in Short-Run Nominal Exchange Rates: A M ultivariate Generalized ARCH Model", Review of E conomics and Statistics, $72,498\{505$.

[6] Bollerslev, T., R.Y. Chou and K.F. K roner, 1992, \ARCH Modelling in Finance: A Review of the Theory and Empirical Evidence", J ournal of E conometrics, 52, 5 - 59.

[7] Bollerslev, T., R.F. Engle and J.M. Wooldridge, 1988, \A Capital A sset Pricing Model with Time-Varying Covariances", J ournal of Political Economy, 96, 116 \{ 131.

[8] B ollerslev, T. and J .M. Wooldridge, 1992, \Quasi-M aximum Likelihood Estimation and Inference in Dynamic Models with Time-Varying Covariances", Econometric Reviews, 11, $143\{172$.

[9] Diebold, F.X. and M. Nerlove, 1989, IThe Dynamics of Exchange Rate Volatility: A Multivariate Latent Factor ARCH Model", J ournal of A pplied Econometrics, 4, $1\{21$.

[10] Engel, C. and A.P. Rodrigues, 1989, ITests of International CAPM with TimeVarying Covariances", J ournal of A pplied E conometrics, 4, $119\{138$. 
[11] Engle, R.F., C.W.J . Granger and D. K raft, 1984, I Combining Competing Forecasts of $\mathrm{In}^{\circ}$ ation Using a Bivariate ARCH Model ", J ournal of Economic Dynamics and Control, 8, 151 - 165.

[12] Engle, R.F., D.F. Hendry and D. Trumble, 1985, ISmall-Sample Properties of ARCH Estimators and Tests", Canadian J ournal of E conomics, 18, 66 - 93.

[13] Engle, R.F. and K.F. Kroner, 1995, \M ultivariate Simultaneous Generalized ARCH", Econometric Theory, 11, $122\{150$.

[14] Engle, R.F., V.K. Ng and M . R othschild, 1990, \A sset P ricing with a Factor-A RCH Covariance Structure: Empirical Estimates for Treasury Bills", J ournal of Econometrics, 45, $213\{237$.

[15] Gourieroux, C., 1997, ARCH Models and Financial Applications, New York: Springer.

[16] K arolyi, G.A., 1995, \A M ultivariate GA RCH M odel of International Transmissions of Stock Returns and Volatility: The Case of the United States and Canada", J ournal of Business and Economic Statistics, 13, $11\{25$.

[17] Kroner, K.F. and S. Claessens, 1991, IOptimal Dynamic Hedging Portfolios and the Currency Composition of External Debt", J ournal of International Money and Finance, 10, $131\{148$.

[18] Li, W.K. and T.K. Mak, 1994, IOn the Squared Residual Autocorrelations in NonLinear Time Series with Conditional Heteroscedasticity", J ournal of Time Series Analysis, 15, $627\{636$.

[19] Lien, D. and X. Luo, 1994, \Multiperiod Hedging in the Presence of Conditional Heteroscedasticity", J ournal of Futures Markets, 14, 927 \{ 955.

[20] Lien, D., Y .K. T se and A.K.C. T sui, 1998, \ E valuating the Hedging Performance of GARCH Strategies", mimeo, Department of E conomics, National University of Singapore, downloadable at: ht tp: // uww fas. nus. edu. sg/ ecs/st aff / ecst seyk/ tykhpw ht nh

[21] Ling, S. and W.K. Li, 1997, IDiagnostic Checking of Nonlinear M ultivariate Time Series with Multivariate ARCH Errors", J ournal of Time Series Analysis, 18, 447 $-464$. 
[22] Lumsdaine, R.L., 1995, \F inite-Sample P roperties of the M aximum Likelihood E stimator in $\operatorname{GARCH}(1,1)$ and IGARCH $(1,1)$ Models: A M onte Carlo Investigation", J ournal of Business and Economic Statistics, 13, 1 - 10.

[23] Lumsdaine, R.L., 1996, IConsistency and Asymptotic Normality of the QuasiMaximum Likelihood Estimator in $\operatorname{IGARCH}(1,1)$ and Covariance Stationary GARCH $(1,1)$ M odels", Econometrica, 64, 575 - 596.

[24] T se, Y.K., 1998, \A Test for Constant Correlations in a Multivariate GA RCH M odel" , mimeo, D epartment of Economics, National University of Singapore, downloadable at: htt p: / / www fas. nus. edu. sg/ ecs/ st af f / ecst seyk/t ykhpw ht nh

[25] Weiss, A.A., 1986, \Asymptotic Theory for ARCH Models: Estimation and Testing", E conometric Theory, 2, 107 - 131. 
Table 1.1: Estimated Bias and MSE of the QM LE of Bivariate VC-MGARCH(1, 1) M odels

\begin{tabular}{|c|c|c|c|c|c|c|c|c|}
\hline \multirow[b]{2}{*}{ Parameters } & \multicolumn{4}{|c|}{ 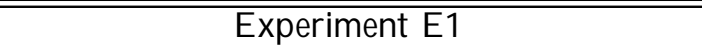 } & \multicolumn{4}{|c|}{ 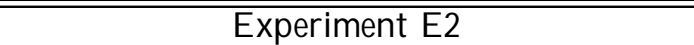 } \\
\hline & True Value & Sample Size & Bias & MSE & True Value & Sample Size & Bias & MSE \\
\hline \multirow{3}{*}{$!_{1}$} & 0.4 & 500 & 0.0907 & 0.0687 & 0.4 & 500 & 0.1166 & 0.0993 \\
\hline & & 1000 & 0.0363 & 0.0194 & & 1000 & 0.0487 & 0.0273 \\
\hline & & 1500 & 0.0266 & 0.0116 & & 1500 & 0.0328 & 0.0157 \\
\hline \multirow[t]{3}{*}{$\Theta_{1}$} & 0.8 & 500 & $\{0.0135$ & 0.0033 & 0.8 & 500 & $\{0.0183$ & 0.0043 \\
\hline & & 1000 & $\{0.0056$ & 0.0012 & & 1000 & $\{0.0070$ & 0.0016 \\
\hline & & 1500 & $\{0.0046$ & 0.0008 & & 1500 & $\{0.0050$ & 0.0010 \\
\hline \multirow[t]{3}{*}{1} & 0.15 & 500 & $\{0.0007$ & 0.0013 & 0.15 & 500 & 0.0005 & 0.0017 \\
\hline & & 1000 & $\{0.0005$ & 0.0006 & & 1000 & $\{0.0010$ & 0.0008 \\
\hline & & 1500 & 0.0005 & 0.0004 & & 1500 & $\{0.0004$ & 0.0005 \\
\hline \multirow[t]{3}{*}{$! 2$} & 0.2 & 500 & 0.0313 & 0.0095 & 0.2 & 500 & 0.0364 & 0.0118 \\
\hline & & 1000 & 0.0132 & 0.0031 & & 1000 & 0.0123 & 0.0040 \\
\hline & & 1500 & 0.0076 & 0.0017 & & 1500 & 0.0089 & 0.0024 \\
\hline \multirow[t]{3}{*}{$\mathbb{R}_{2}$} & 0.7 & 500 & $\{0.0170$ & 0.0062 & 0.7 & 500 & $\{0.0230$ & 0.0079 \\
\hline & & 1000 & $\{0.0094$ & 0.0023 & & 1000 & $\{0.0075$ & 0.0031 \\
\hline & & 1500 & $\{0.0043$ & 0.0015 & & 1500 & $\{0.0047$ & 0.0018 \\
\hline \multirow[t]{3}{*}{2} & 0.2 & 500 & $\{0.0018$ & 0.0023 & 0.2 & 500 & 0.0011 & 0.0030 \\
\hline & & 1000 & 0.0013 & 0.0010 & & 1000 & $\{0.0003$ & 0.0013 \\
\hline & & 1500 & $\{0.0005$ & 0.0008 & & 1500 & $\{0.0005$ & 0.0009 \\
\hline \multirow[t]{3}{*}{$1 / 2$} & 0.7 & 500 & $\{0.0011\}$ & 0.0028 & 0.2 & 500 & $\{0.0008$ & 0.0077 \\
\hline & & 1000 & $\{0.0227$ & 0.0084 & & 1000 & $\{0.0012$ & 0.0034 \\
\hline & & 1500 & 0.0010 & 0.0009 & & 1500 & 0.0001 & 0.0022 \\
\hline \multirow[t]{3}{*}{$\mu_{1}$} & 0.8 & 500 & $\{0.0018$ & 0.0014 & 0.8 & 500 & $\{0.0358$ & 0.0181 \\
\hline & & 1000 & $\{0.0090$ & 0.0023 & & 1000 & $\{0.0194$ & 0.0065 \\
\hline & & 1500 & 0.0011 & 0.0004 & & 1500 & $\{0.0111$ & 0.0029 \\
\hline \multirow[t]{3}{*}{$\mu_{2}$} & 0.1 & 500 & $\{0.0006$ & 0.0008 & 0.1 & 500 & 0.0043 & 0.0016 \\
\hline & & 1000 & $\{0.0064$ & 0.0014 & & 1000 & 0.0023 & 0.0008 \\
\hline & & 1500 & 0.0005 & 0.0003 & & 1500 & 0.0011 & 0.0004 \\
\hline
\end{tabular}

N otes: See equations (8), (9) and (10) for the data generating process. 
Table 1.2: Estimated Bias and MSE of the QMLE of Bivariate VC-MGARCH $(1,1)$ M odels

\begin{tabular}{|c|c|c|c|c|c|c|c|c|}
\hline \multirow[b]{2}{*}{ Parameters } & \multicolumn{4}{|c|}{ 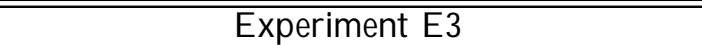 } & \multicolumn{4}{|c|}{ 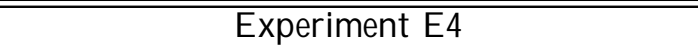 } \\
\hline & True Value & Sample Size & Bias & MSE & True Value & Sample Size & Bias & MSE \\
\hline \multirow[t]{3}{*}{$!_{1}$} & 0.4 & 500 & 0.0280 & 0.0177 & 0.4 & 500 & 0.0315 & 0.0188 \\
\hline & & 1000 & 0.0153 & 0.0077 & & 1000 & 0.0114 & 0.0088 \\
\hline & & 1500 & 0.0056 & 0.0044 & & 1500 & 0.0051 & 0.0052 \\
\hline \multirow[t]{3}{*}{$\Theta_{1}$} & 0.5 & 500 & $\{0.0184$ & 0.0104 & 0.5 & 500 & $\{0.0181$ & 0.0109 \\
\hline & & 1000 & $\{0.0092$ & 0.0045 & & 1000 & $\{0.0067$ & 0.0051 \\
\hline & & 1500 & 0.0028 & 0.0027 & & 1500 & $\{0.0025$ & 0.0031 \\
\hline \multirow[t]{3}{*}{1} & 0.3 & 500 & 0.0005 & 0.0041 & 0.3 & 500 & $\{0.0032$ & 0.0042 \\
\hline & & 1000 & 0.0021 & 0.0020 & & 1000 & $\{0.0019$ & 0.0021 \\
\hline & & 1500 & $\{0.0010$ & 0.0015 & & 1500 & $\{0.0022$ & 0.0015 \\
\hline \multirow[t]{3}{*}{$!_{2}$} & 0.2 & 500 & 0.0177 & 0.0064 & 0.2 & 500 & 0.0219 & 0.0081 \\
\hline & & 1000 & 0.0092 & 0.0031 & & 1000 & 0.0109 & 0.0032 \\
\hline & & 1500 & 0.0072 & 0.0021 & & 1500 & 0.0089 & 0.0024 \\
\hline \multirow[t]{3}{*}{$\mathbb{R}_{2}$} & 0.4 & 500 & $\{0.0409$ & 0.0335 & 0.5 & 500 & $\{0.0352$ & 0.0268 \\
\hline & & 1000 & $\{0.0166$ & 0.0162 & & 1000 & $\{0.0188$ & 0.0110 \\
\hline & & 1500 & $\{0.0153$ & 0.0118 & & 1500 & $\{0.0089$ & 0.0074 \\
\hline \multirow[t]{3}{*}{2} & 0.2 & 500 & 0.0011 & 0.0038 & 0.2 & 500 & $\{0.0008$ & 0.0034 \\
\hline & & 1000 & $\{0.0007$ & 0.0018 & & 1000 & 0.0016 & 0.0017 \\
\hline & & 1500 & 0.0005 & 0.0013 & & 1500 & 0.0021 & 0.0013 \\
\hline \multirow[t]{3}{*}{$1 / 2$} & 0.5 & 500 & $\{0.0093$ & 0.0079 & 0.2 & 500 & 0.0002 & 0.0139 \\
\hline & & 1000 & 0.0012 & 0.0037 & & 1000 & 0.0007 & 0.0068 \\
\hline & & 1500 & $\{0.0010$ & 0.0024 & & 1500 & 0.0001 & 0.0041 \\
\hline \multirow[t]{3}{*}{$\mu_{1}$} & 0.7 & 500 & $\{0.0136$ & 0.0052 & 0.6 & 500 & $\{0.0137\}$ & 0.0055 \\
\hline & & 1000 & $\{0.0054$ & 0.0022 & & 1000 & $\{0.0035$ & 0.0023 \\
\hline & & 1500 & $\{0.0031$ & 0.0014 & & 1500 & $\{0.0058$ & 0.0016 \\
\hline \multirow[t]{3}{*}{$\mu_{2}$} & 0.2 & 500 & 0.0022 & 0.0016 & 0.3 & 500 & 0.0035 & 0.0023 \\
\hline & & 1000 & 0.0004 & 0.0008 & & 1000 & $\{0.0009$ & 0.0010 \\
\hline & & 1500 & 0.0003 & 0.0005 & & 1500 & 0.0019 & 0.0007 \\
\hline
\end{tabular}

N otes: See equations (8), (9) and (10) for the data generating process. 
Table 2: Summary Statistics of the Di ßerenced Logarithmic Series of Various Data Sets

\begin{tabular}{|c|c|c|c|c|c|c|c|c|c|}
\hline Variable (Code) & M ean & Std Dev & M Minimum & "Maximum & Std Skewness & Std K urtosis & 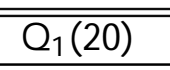 & 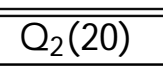 & Num of Obs \\
\hline \multicolumn{10}{|c|}{ Panel A: Forex Market Data (DS1) } \\
\hline $\begin{array}{l}\text { B ritish Pound (B) } \\
\text { Deutschmark (D) }\end{array}$ & $\begin{array}{r}0.0008 \\
\{0.0025\end{array}$ & $\begin{array}{l}0.6498 \\
0.6919\end{array}$ & $\begin{array}{l}\{4.3306 \\
\{3.4671\end{array}$ & $\begin{array}{l}3.2467 \\
3.3440\end{array}$ & $\begin{array}{l}\{28.6798 \\
\{28.2742\end{array}$ & $\begin{array}{r}125.0248 \\
95.0182\end{array}$ & $\begin{array}{l}18.4091 \\
12.1631\end{array}$ & $\begin{array}{l}422.5185 \\
211.7246\end{array}$ & $\begin{array}{l}2137 \\
2137\end{array}$ \\
\hline \multicolumn{10}{|c|}{ Panel B: Bond Market Data (DS2) } \\
\hline 3-M onth T -B ill (M) & $\{0.1019$ & 2.3643 & $\{21.2535$ & 10.4069 & $\{363.1040$ & 228.7802 & 65.0449 & 106.4135 & 850 \\
\hline 1-Year T-Note (0) & $\{0.1104$ & 2.1071 & $\{14.3009$ & 6.5305 & $\{138.6335$ & 108.3323 & 104.6519 & 91.8969 & 850 \\
\hline 10-Year $\mathrm{T}$-B ond $(\mathrm{T})$ & $\{0.1102$ & 1.6528 & $\{7.7080$ & 5.5091 & $\{27.0643$ & 48.6885 & 72.0995 & 65.6332 & 850 \\
\hline \multicolumn{10}{|c|}{ Panel C: Stock M arket Data (DS3) } \\
\hline Hong Kong $(\mathrm{H})$ & 0.5218 & 3.3224 & $\{10.3635$ & 12.0917 & $\{31.4482$ & 26.3981 & 38.0765 & 28.1933 & 340 \\
\hline J apan (J) & $\{0.2015$ & 3.2499 & $\{10.2969$ & 11.5091 & $\{13.3198$ & 30.9661 & 24.8226 & 34.2806 & 340 \\
\hline Singapore (S) & 0.0306 & 2.3391 & $\{13.5471$ & 6.9306 & $\{96.0536$ & 55.8701 & 43.5073 & 87.6590 & 340 \\
\hline
\end{tabular}

Notes: $\quad Q_{1}(20)$ is the Box-Pierce portmanteau statistic of the di ßerenced logarithmic series based on the autocorrelation coe \pm cients up to order 20. Similarly, $\mathrm{Q}_{2}(20)$ is the portmanteau statistic of the squared di ßerenced logarithmic series. 
Table 3: Estimation Results of CC-M GARCH $(1,1)$ M odels

\begin{tabular}{|c|c|c|c|c|c|c|}
\hline$\overline{\text { Data }}$ & K & Variable & $!$ & ${ }^{\circledR}$ & & Correlations \\
\hline DS1 & 2 & $\begin{array}{l}\text { B } \\
\text { D }\end{array}$ & $\begin{array}{c}0.0117 \\
(0.0030) \\
0.0162 \\
(0.0042)\end{array}$ & $\begin{array}{c}0.9221 \\
(0.0145) \\
0.9274 \\
(0.0141)\end{array}$ & $\begin{array}{c}0.0464 \\
(0.0081) \\
0.0362 \\
(0.0067)\end{array}$ & $\begin{aligned} 1 / B D= & 0.7168 \\
& (0.0107)\end{aligned}$ \\
\hline DS2 & 2 & $\begin{array}{l}\text { M } \\
0\end{array}$ & $\begin{array}{c}0.6598 \\
(0.2739) \\
0.3558 \\
(0.0913)\end{array}$ & $\begin{array}{c}0.6259 \\
(0.1127) \\
0.8129 \\
(0.0270)\end{array}$ & $\begin{array}{c}0.2249 \\
(0.0828) \\
0.0961 \\
(0.0255)\end{array}$ & $1 /$ 阴O $=0.7623$ \\
\hline & 2 & $\begin{array}{l}\mathrm{M} \\
\mathrm{T}\end{array}$ & $\begin{array}{c}0.5959 \\
(0.2888) \\
0.2605 \\
(0.0720)\end{array}$ & $\begin{array}{c}0.5883 \\
(0.1454) \\
0.8384 \\
(0.0288)\end{array}$ & $\begin{array}{c}0.3033 \\
(0.1353) \\
0.0605 \\
(0.0205)\end{array}$ & $\begin{aligned} 1 / R M T & =0.5232 \\
& (0.0322)\end{aligned}$ \\
\hline & 2 & $\begin{array}{l}0 \\
T\end{array}$ & $\begin{array}{c}0.2241 \\
(0.0781) \\
0.2116 \\
(0.0576)\end{array}$ & $\begin{array}{c}0.8284 \\
(0.0392) \\
0.8591 \\
(0.0244)\end{array}$ & $\begin{array}{c}0.1215 \\
(0.0377) \\
0.0589 \\
(0.0154)\end{array}$ & $\begin{aligned} 1 / 0 \mathrm{~T}= & 0.8249 \\
& (0.0133)\end{aligned}$ \\
\hline & 3 & $\begin{array}{l}M \\
0 \\
T\end{array}$ & $\begin{array}{c}0.6020 \\
(0.2908) \\
0.3440 \\
(0.0871) \\
0.2278 \\
(0.0663)\end{array}$ & $\begin{array}{c}0.6568 \\
(0.1224) \\
0.8152 \\
(0.0301) \\
0.8603 \\
(0.0285)\end{array}$ & $\begin{array}{c}0.2050 \\
(0.0841) \\
0.0971 \\
(0.0237) \\
0.0505 \\
(0.0139)\end{array}$ & $\begin{aligned} 1 / \mathrm{B} O= & 0.7627 \\
& (0.0225) \\
1 / \mathrm{BT} \mathrm{T}= & 0.5264 \\
& (0.0340) \\
1 / \otimes \mathrm{T}= & 0.8246 \\
& (0.0135)\end{aligned}$ \\
\hline DS3 & 2 & $\begin{array}{l}\mathrm{H} \\
\mathrm{J}\end{array}$ & $\begin{array}{c}0.6250 \\
(0.4604) \\
0.9569 \\
(0.6010)\end{array}$ & $\begin{array}{c}0.8721 \\
(0.0471) \\
0.8079 \\
(0.0774)\end{array}$ & $\begin{array}{c}0.0999 \\
(0.0507) \\
0.1006 \\
(0.0481)\end{array}$ & $\begin{aligned} 1 / R J & =0.2073 \\
& (0.0600)\end{aligned}$ \\
\hline & 2 & $\begin{array}{l}\mathrm{H} \\
\mathrm{S}\end{array}$ & $\begin{array}{c}1.0243 \\
(0.5177) \\
0.6106 \\
(2.1266)\end{array}$ & $\begin{array}{c}0.8499 \\
(0.0414) \\
0.8186 \\
(0.4753)\end{array}$ & $\begin{array}{c}0.0918 \\
(0.0404) \\
0.0829 \\
(0.1192)\end{array}$ & $\begin{aligned} 1 / R S & =0.5645 \\
& (0.0519)\end{aligned}$ \\
\hline & 2 & $\begin{array}{l}\mathrm{J} \\
\mathrm{S}\end{array}$ & $\begin{array}{c}0.8439 \\
(0.5115) \\
0.5639 \\
(0.6395)\end{array}$ & $\begin{array}{c}0.8233 \\
(0.0625) \\
0.8156 \\
(0.1408)\end{array}$ & $\begin{array}{c}0.0961 \\
(0.0406) \\
0.0966 \\
(0.0545)\end{array}$ & $\begin{aligned} 1 / R S= & 0.3149 \\
& (0.0572)\end{aligned}$ \\
\hline & 3 & $\begin{array}{l}\mathrm{H} \\
\mathrm{J} \\
\mathrm{S}\end{array}$ & $\begin{array}{c}1.0140 \\
(0.5099) \\
0.8652 \\
(0.5460) \\
0.7917 \\
(1.9858)\end{array}$ & $\begin{array}{c}0.8522 \\
(0.0389) \\
0.8200 \\
(0.0686) \\
0.7867 \\
(0.4195)\end{array}$ & $\begin{array}{c}0.0900 \\
(0.0403) \\
0.0969 \\
(0.0425) \\
0.0825 \\
(0.0863)\end{array}$ & $\begin{aligned} 1 / \mathrm{RJ}= & 0.2146 \\
& (0.0607) \\
1 / \mathrm{RS}= & 0.5663 \\
& (0.0524) \\
1 / \mathrm{RS}_{=}= & 0.3220 \\
& (0.0600)\end{aligned}$ \\
\hline
\end{tabular}

N otes: The ${ }^{-}$gures in parentheses are standard errors. 
Table 4: Estimation Results of VC-MGARCH $(1,1)$ M odels

\begin{tabular}{|c|c|c|c|c|c|c|c|c|}
\hline$\overline{\text { Data }}$ & $\overline{\bar{K}}$ & Variable & $\overline{I !}$ & $\stackrel{(B)}{ }$ & & $\mu_{1}$ & $\mu_{2}$ & Correlations \\
\hline DS1 & 2 & $\begin{array}{l}\text { B } \\
\text { D }\end{array}$ & $\begin{array}{c}0.0059 \\
(0.0018) \\
0.0073 \\
(0.0022)\end{array}$ & $\begin{array}{c}0.9323 \\
(0.0110) \\
0.9415 \\
(0.0095)\end{array}$ & $\begin{array}{c}0.0516 \\
(0.0076) \\
0.0419 \\
(0.0063)\end{array}$ & $\begin{array}{c}0.9728 \\
(0.0037)\end{array}$ & $\begin{array}{c}0.0187 \\
(0.0026)\end{array}$ & $\begin{aligned} 1 / B D= & 0.8987 \\
& (0.0192)\end{aligned}$ \\
\hline DS2 & 2 & $\begin{array}{l}M \\
0\end{array}$ & $\begin{array}{c}0.3935 \\
(0.2544) \\
0.2724 \\
(0.0810)\end{array}$ & $\begin{array}{c}0.7177 \\
(0.1280) \\
0.8184 \\
(0.0286)\end{array}$ & $\begin{array}{c}0.1993 \\
(0.0976) \\
0.1151 \\
(0.0303)\end{array}$ & $\begin{array}{c}0.8582 \\
(0.0696)\end{array}$ & $\begin{array}{c}0.0502 \\
(0.0228)\end{array}$ & $\begin{aligned} 1 / M_{1} O= & 0.8217 \\
& (0.0267)\end{aligned}$ \\
\hline & 2 & $\begin{array}{l}\mathrm{M} \\
\mathrm{T}\end{array}$ & $\begin{array}{c}0.5790 \\
(0.2787) \\
0.2596 \\
(0.0730)\end{array}$ & $\begin{array}{c}0.5968 \\
(0.1409) \\
0.8353 \\
(0.0305)\end{array}$ & $\begin{array}{c}0.3014 \\
(0.1331) \\
0.0627 \\
(0.0211)\end{array}$ & $\begin{array}{c}0.6564 \\
(0.0319)\end{array}$ & $\begin{array}{c}0.0673 \\
(0.0399)\end{array}$ & $\begin{aligned} 1 / \mathbb{R} T= & 0.5433 \\
& (0.0396)\end{aligned}$ \\
\hline & 2 & $\begin{array}{l}0 \\
T\end{array}$ & $\begin{array}{c}0.2214 \\
(0.0755) \\
0.2210 \\
(0.0594)\end{array}$ & $\begin{array}{c}0.8232 \\
(0.0378) \\
0.8534 \\
(0.0246)\end{array}$ & $\begin{array}{c}0.1295 \\
(0.0384) \\
0.0615 \\
(0.0157)\end{array}$ & $\begin{array}{c}0.4910 \\
(0.1293)\end{array}$ & $\begin{array}{c}0.0474 \\
(0.0237)\end{array}$ & $\begin{aligned} 1 / 0 \mathrm{~T}= & 0.8345 \\
& (0.0142)\end{aligned}$ \\
\hline & 3 & $\begin{array}{l}M \\
0 \\
T\end{array}$ & $\begin{array}{c}0.3897 \\
(0.2770) \\
0.2657 \\
(0.0813) \\
0.2042 \\
(0.0658)\end{array}$ & $\begin{array}{c}0.7295 \\
(0.1351) \\
0.8285 \\
(0.0307) \\
0.8691 \\
(0.0273)\end{array}$ & $\begin{array}{c}0.1828 \\
(0.0941) \\
0.1035 \\
(0.0254) \\
0.0515 \\
(0.0134)\end{array}$ & $\begin{array}{c}0.9389 \\
(0.0341)\end{array}$ & $\begin{array}{c}0.0187 \\
(0.0095)\end{array}$ & $\begin{aligned} 1 / \mathrm{B} O_{\mathrm{O}}= & 0.7975 \\
& (0.0272) \\
1 / \mathrm{BM}= & 0.5580 \\
& (0.0453) \\
1 / \otimes \mathrm{T}= & 0.8421 \\
& (0.0194)\end{aligned}$ \\
\hline DS3 & 2 & $\begin{array}{l}\mathrm{H} \\
\mathrm{J}\end{array}$ & $\begin{array}{c}0.6717 \\
(0.4534) \\
0.8859 \\
(0.5768)\end{array}$ & $\begin{array}{c}0.8703 \\
(0.0450) \\
0.8131 \\
(0.0790)\end{array}$ & $\begin{array}{c}0.0986 \\
(0.0504) \\
0.1012 \\
(0.0486)\end{array}$ & $\begin{array}{c}0.6545 \\
(0.1172)\end{array}$ & $\begin{array}{c}0.0750 \\
(0.0533)\end{array}$ & $\begin{aligned} 1 / A J= & 0.1968 \\
& (0.0734)\end{aligned}$ \\
\hline & 2 & $\begin{array}{l}\mathrm{H} \\
\mathrm{S}\end{array}$ & $\begin{array}{c}0.8115 \\
(0.4599) \\
0.5684 \\
(1.5522)\end{array}$ & $\begin{array}{c}0.8719 \\
(0.0373) \\
0.8190 \\
(0.3632)\end{array}$ & $\begin{array}{c}0.0845 \\
(0.0335) \\
0.0945 \\
(0.1169)\end{array}$ & $\begin{array}{c}0.8398 \\
(0.0606)\end{array}$ & $\begin{array}{c}0.0745 \\
(0.0272)\end{array}$ & $\begin{aligned} 1 / A S= & 0.7314 \\
& (0.1174)\end{aligned}$ \\
\hline & 2 & $\begin{array}{l}\mathrm{J} \\
\mathrm{s}\end{array}$ & $\begin{array}{c}0.8021 \\
(0.4693) \\
0.5539 \\
(0.6726)\end{array}$ & $\begin{array}{c}0.8316 \\
(0.0573) \\
0.8181 \\
(0.1505)\end{array}$ & $\begin{array}{c}0.0900 \\
(0.0371) \\
0.0943 \\
(0.0541)\end{array}$ & $\begin{array}{c}0.9772 \\
(0.0092)\end{array}$ & $\begin{array}{c}0.0197 \\
(0.0085)\end{array}$ & $\begin{aligned} 1 / 2 S= & 0.5691 \\
& (0.1326)\end{aligned}$ \\
\hline & 3 & $\begin{array}{l}\mathrm{H} \\
\mathrm{J} \\
\mathrm{S}\end{array}$ & $\begin{array}{c}0.9366 \\
(0.4684) \\
0.8595 \\
(0.5063) \\
0.8180 \\
(1.3114)\end{array}$ & $\begin{array}{c}0.8646 \\
(0.0368) \\
0.8157 \\
(0.0651) \\
0.7763 \\
(0.2764)\end{array}$ & $\begin{array}{c}0.0824 \\
(0.0366) \\
0.1014 \\
(0.0415) \\
0.0922 \\
(0.0631)\end{array}$ & $\begin{array}{c}0.7343 \\
(0.1851)\end{array}$ & $\begin{array}{c}0.0623 \\
(0.0305)\end{array}$ & $\begin{aligned} 1 / R J= & 0.2048 \\
& (0.0779) \\
1 / R S= & 0.6207 \\
& (0.0682) \\
1 / R S= & 0.3333 \\
& (0.0696)\end{aligned}$ \\
\hline
\end{tabular}

N otes: The ${ }^{-}$gures in parentheses are standard errors. 
Table 5: Diagnostic Checks for the Constant-Correlation and Varying-Correlation M odels

\begin{tabular}{|c|c|c|c|c|c|c|c|c|c|}
\hline \multirow[b]{2}{*}{ Tests } & \multirow{2}{*}{$\frac{\text { Forex Market (DS1) }}{(B, D)}$} & \multicolumn{4}{|c|}{ B ond Market (DS2) } & \multicolumn{4}{|c|}{ Stock Market (DS3) } \\
\hline & & $(\mathrm{M}, \mathrm{O})$ & $(\mathrm{M}, \mathrm{T})$ & $(0, T)$ & $(\mathrm{M}, \mathrm{O}, \mathrm{T})$ & $(\mathrm{H}, \mathrm{J})$ & $(\mathrm{H}, \mathrm{S})$ & $(\mathrm{J}, \mathrm{S})$ & $(H, J, S)$ \\
\hline \multicolumn{10}{|c|}{ Panel A: CC-MGARCH(1, 1) Model } \\
\hline $\mathrm{Q}_{1}(20)$ & 16.730 & 14.530 & 15.746 & 26.488 & 14.325 & 25.496 & 25.485 & 18.518 & 25.330 \\
\hline $\mathrm{Q}_{2}(20)$ & 12.247 & 24.797 & 22.631 & 22.447 & 25.029 & 18.554 & 22.235 & 22.293 & 18.265 \\
\hline $\mathrm{Q}_{3}(20)$ & & & & & 22.596 & & & & 22.199 \\
\hline $\mathrm{Q}_{11}(20)$ & 11.005 & 14.692 & 17.396 & 7.175 & 13.611 & 25.336 & 27.403 & 24.091 & 27.494 \\
\hline $\mathrm{Q}_{22}(20)$ & 22.691 & 7.124 & 17.300 & 17.301 & 6.977 & 24.291 & 14.405 & 13.082 & 25.297 \\
\hline $\mathrm{Q}_{33}(20)$ & & & & & 17.478 & & & & 14.284 \\
\hline $\mathrm{Q}_{12}(20)$ & 51.313 & 4.601 & 7.758 & 10.553 & 4.252 & 19.081 & 21.774 & 21.306 & 17.629 \\
\hline $\mathrm{Q}_{13}(20)$ & & & & & 7.513 & & & & 21.892 \\
\hline $\mathrm{Q}_{23}(20)$ & & & & & 10.505 & & & & 23.480 \\
\hline LMC & 0.087 & 1.570 & 6.050 & 1.233 & 2.896 & 1.149 & 7.239 & 1.169 & 9.987 \\
\hline \multicolumn{10}{|c|}{ Panel B: VC-MGARCH $(1,1)$ Model } \\
\hline $\mathrm{Q}_{1}(20)$ & 16.934 & 14.970 & 15.742 & 26.711 & 14.724 & 25.481 & 25.196 & 18.501 & 25.095 \\
\hline $\mathrm{Q}_{2}(20)$ & 9.745 & 25.898 & 22.625 & 22.466 & 25.771 & 18.534 & 22.285 & 22.278 & 18.247 \\
\hline $\mathrm{Q}_{3}(20)$ & & & & & 22.596 & & & & 22.200 \\
\hline $\mathrm{Q}_{11}(20)$ & 7.022 & 12.469 & 17.192 & 7.406 & 11.840 & 25.639 & 27.110 & 23.923 & 27.680 \\
\hline $\mathrm{Q}_{22}(20)$ & 14.752 & 6.970 & 17.252 & 17.246 & 6.728 & 24.322 & 13.403 & 13.235 & 25.457 \\
\hline $\mathrm{Q}_{33}(20)$ & & & & & 17.436 & & & & 13.473 \\
\hline $\mathrm{Q}_{12}(20)$ & 27.998 & 3.664 & 7.655 & 10.626 & 3.593 & 19.309 & 21.292 & 21.923 & 18.041 \\
\hline $\mathrm{Q}_{13}(20)$ & & & & & 7.001 & & & & 21.972 \\
\hline $\mathrm{Q}_{23}(20)$ & & & & & 10.333 & & & & 22.320 \\
\hline LR & 298.825 & 38.749 & 10.980 & 9.094 & 31.929 & 3.567 & 11.040 & 5.272 & 10.309 \\
\hline
\end{tabular}

Notes: $\quad Q_{i}(20)$ are the Box-Pierce portmanteau statistics based on the autocorrelation coe \pm cients of order up to 20 for the standardised residuals of variabe i. Similarly, $\mathrm{Q}_{\mathrm{ij}}(20)$ are the portmanteau statistics based on the autocorrelation coe \pm cients of order up to 20 for the products of the standardised residuals of variables $i$ and $j$. The indices are according to the order of the coded variables in the parentheses (thus $Q_{12}$ in the system $(M, O, T)$ is $Q_{M}$ O). LMC is the Lagrange multiplier test for constant correlations due to T se (1998). LR is the likelihood ratio statistic for $H_{0}: \mu_{1}=\mu_{2}=0$. 
Table 6: Summary Statistics of the Conditional Variance, Covariance and Correlation in the Estimated VC-M GARCH $(1,1)$ M odels

\begin{tabular}{|c|c|c|c|c|c|c|}
\hline Data & System & Statistic & Mean & Std Dev & M inimum & Maximum \\
\hline \multirow[t]{4}{*}{ DS1 } & $(B, D)$ & 3/屋 & 0.4114 & 0.2660 & 0.1151 & 2.1116 \\
\hline & & 3/2 & 0.4678 & 0.2033 & 0.1970 & 1.4227 \\
\hline & & $3 / \mathbb{B} D$ & 0.3176 & 0.2016 & 0.0616 & 1.3518 \\
\hline & & $1 / B D$ & 0.7001 & 0.1395 & 0.3487 & 0.9371 \\
\hline \multirow[t]{21}{*}{ DS2 } & $(M, O)$ & $3 / 2 / 1$ & 4.9094 & 8.1492 & 1.5335 & 100.9584 \\
\hline & & $3 / 2$ & 4.0750 & 3.0793 & 1.7295 & 30.3173 \\
\hline & & 3/4M O & 3.3570 & 3.9179 & 0.7924 & 44.2570 \\
\hline & & $1 / \mathbb{R} 0$ & 0.7519 & 0.0900 & 0.3748 & 0.8691 \\
\hline & $(M, T)$ & 3/2/ & 5.1534 & 10.0503 & 1.5062 & 150.1892 \\
\hline & & $3 / 7$ & 2.5526 & 0.6533 & 1.7611 & 7.2573 \\
\hline & & 3/M T & 1.7786 & 1.4943 & 0.5193 & 19.4827 \\
\hline & & $1 / B_{1} T$ & 0.5217 & 0.0753 & 0.2608 & 0.6277 \\
\hline & $(0, T)$ & $3 / 2 / 6$ & 4.2317 & 3.5258 & 1.5266 & 33.7753 \\
\hline & & 3/2 & 2.5840 & 0.6858 & 1.7321 & 7.2102 \\
\hline & & $3 / 0 T$ & 2.6669 & 1.3140 & 1.3243 & 13.2038 \\
\hline & & $1 / 0 T$ & 0.8257 & 0.0295 & 0.6876 & 0.8496 \\
\hline & $(\mathrm{M}, \mathrm{O}, \mathrm{T})$ & 3/鬲 & 4.8061 & 7.6684 & 1.5843 & 92.8950 \\
\hline & & $3 / 2$ & 4.0039 & 2.8722 & 1.7825 & 27.6077 \\
\hline & & 3/2 & 2.5698 & 0.6126 & 1.7926 & 6.4471 \\
\hline & & 3/M O & 3.2906 & 3.5850 & 1.1341 & 39.3440 \\
\hline & & 3/M T & 1.7629 & 1.2228 & 0.7532 & 12.9837 \\
\hline & & $3 / \oplus T$ & 2.5928 & 1.1185 & 1.4080 & 11.0433 \\
\hline & & $1 / \mathbb{P} 0$ & 0.7580 & 0.0584 & 0.5614 & 0.8324 \\
\hline & & $1 / B M T$ & 0.5302 & 0.0574 & 0.3544 & 0.6400 \\
\hline & & $1 / 0 T$ & 0.8227 & 0.0299 & 0.6916 & 0.8693 \\
\hline \multirow[t]{21}{*}{ DS3 } & $(H, J)$ & $3 / / 4$ & 14.8791 & 7.2350 & 7.7632 & 111.6058 \\
\hline & & $3 / 4$ & 10.4010 & 3.7826 & 5.5870 & 26.3621 \\
\hline & & $3 / 4 / 41$ & 2.3826 & 1.4615 & $\{0.5689$ & 11.2181 \\
\hline & & $1 / R j$ & 0.1961 & 0.0917 & $\{0.0444$ & 0.3586 \\
\hline & $(H, S)$ & $3 / 2 / 4$ & 14.7547 & 6.2244 & 8.5945 & 97.7936 \\
\hline & & $3 / 2$ & 6.0420 & 3.3804 & 3.5594 & 29.9887 \\
\hline & & $3 / / 11 \mathrm{~S}$ & 5.3986 & 2.9302 & 1.4648 & 33.8765 \\
\hline & & 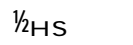 & 0.5667 & 0.1224 & 0.2199 & 0.7989 \\
\hline & $(J, S)$ & $3 / 2$ & 10.3513 & 3.5834 & 5.6473 & 25.0978 \\
\hline & & $3 / 2$ & 5.9269 & 3.3640 & 3.4586 & 29.8087 \\
\hline & & $3 / 4 \mathrm{~S}$ & 2.4025 & 1.7890 & 0.5688 & 12.3114 \\
\hline & & $1 / R S$ & 0.2966 & 0.1217 & 0.0869 & 0.5540 \\
\hline & $(H, J, S)$ & 3/屈 & 14.7097 & 5.9743 & 8.9401 & 95.0937 \\
\hline & & $3 / 4$ & 10.4188 & 3.8265 & 5.5322 & 26.4870 \\
\hline & & $3 / \frac{2}{4}$ & 5.9639 & 2.9457 & 3.9177 & 28.6671 \\
\hline & & 3/A1 J & 2.4613 & 1.3580 & $\{0.3170$ & 10.3302 \\
\hline & & 3/H S & 5.3621 & 2.4003 & 2.3007 & 31.6027 \\
\hline & & $3 / 4 \mathrm{~S}$ & 2.4581 & 1.3627 & 0.7467 & 11.0837 \\
\hline & & $1 / R$ J & 0.2029 & 0.0856 & $\{0.0270$ & 0.3667 \\
\hline & & $1 / \mathbb{R S}$ & 0.5732 & 0.0768 & 0.3544 & 0.6886 \\
\hline & & $1 / R S$ & 0.3115 & 0.0777 & 0.1219 & 0.4721 \\
\hline
\end{tabular}

$\mathrm{N}$ otes: $\quad 3 / 2$ and $3 / \mathrm{mj}$ are the conditional variance and covariance terms, respectively; $1 / \mathrm{h}$ is the conditional correlation. 
Figure 1: Exchange Rates of British Pound and Deutschmark

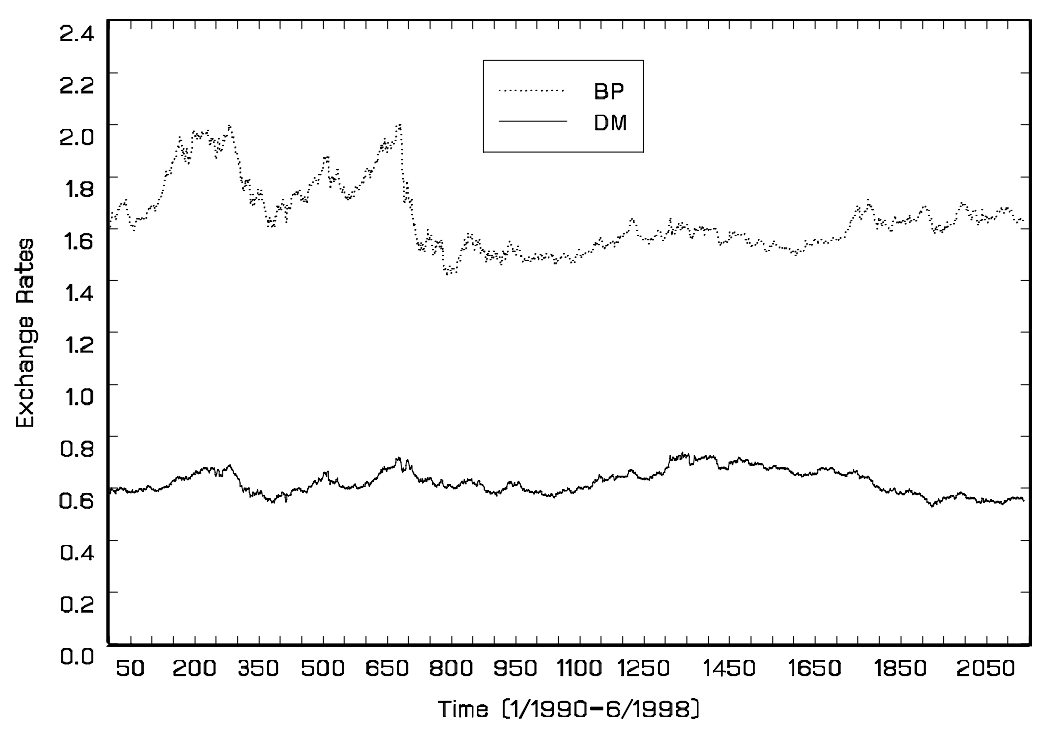

Figure 2: Yields of US Treasury Securities

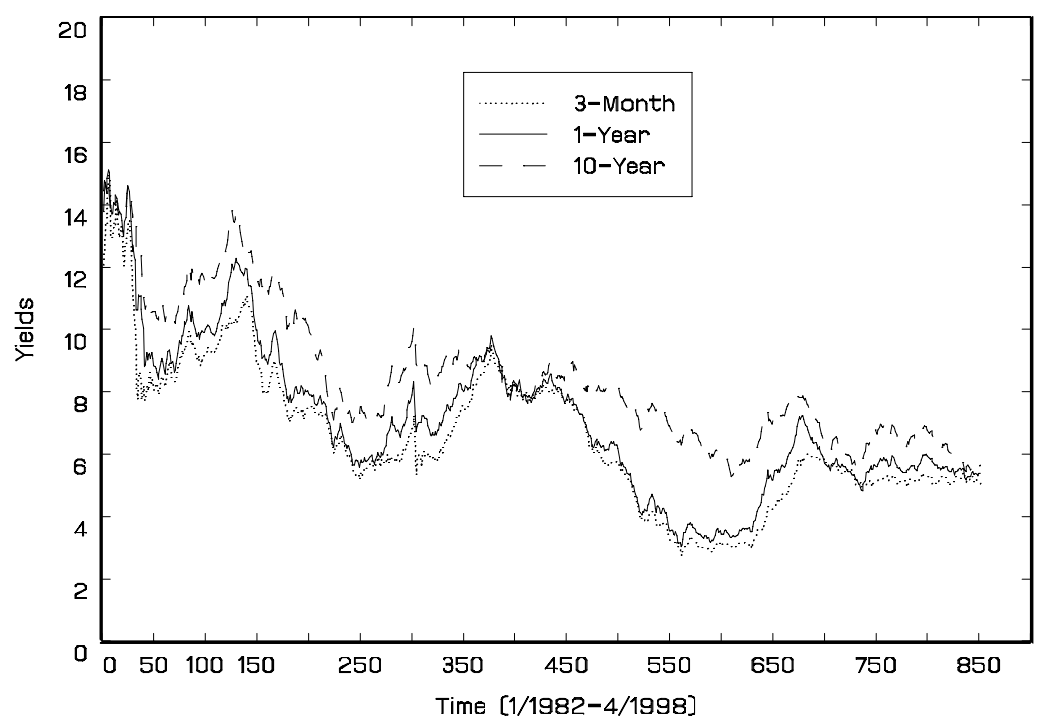

Figure 3: Stock Markets Indices

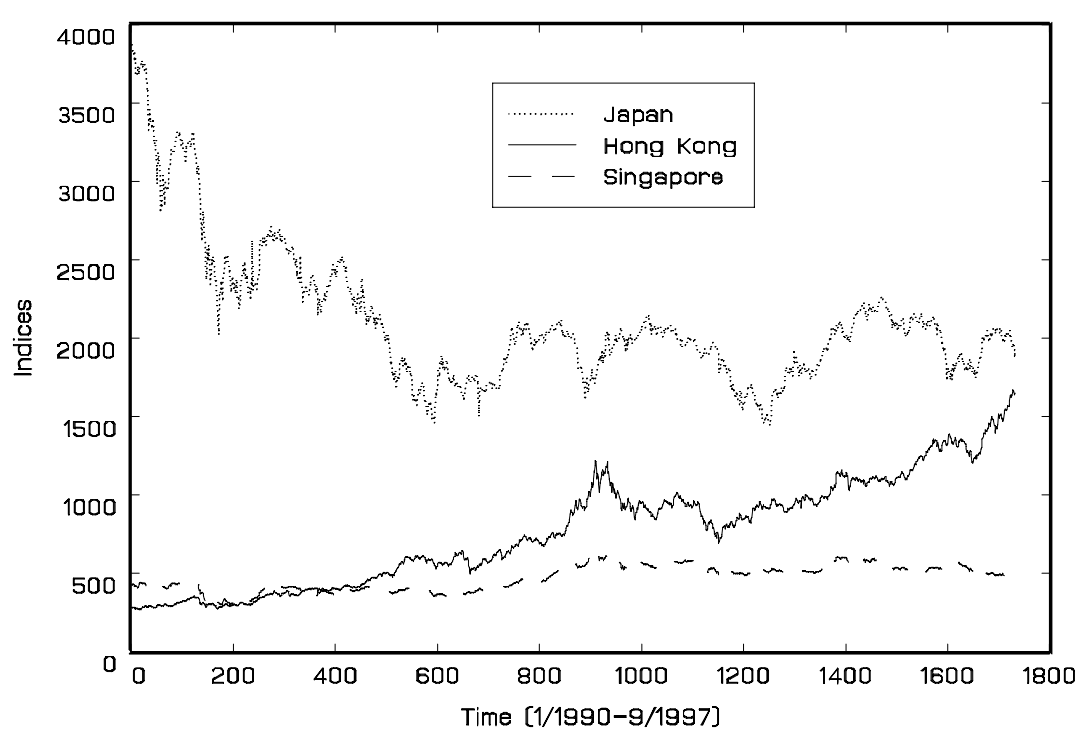


Figure 4: Conditional Correlation Coefficients of [B, D]

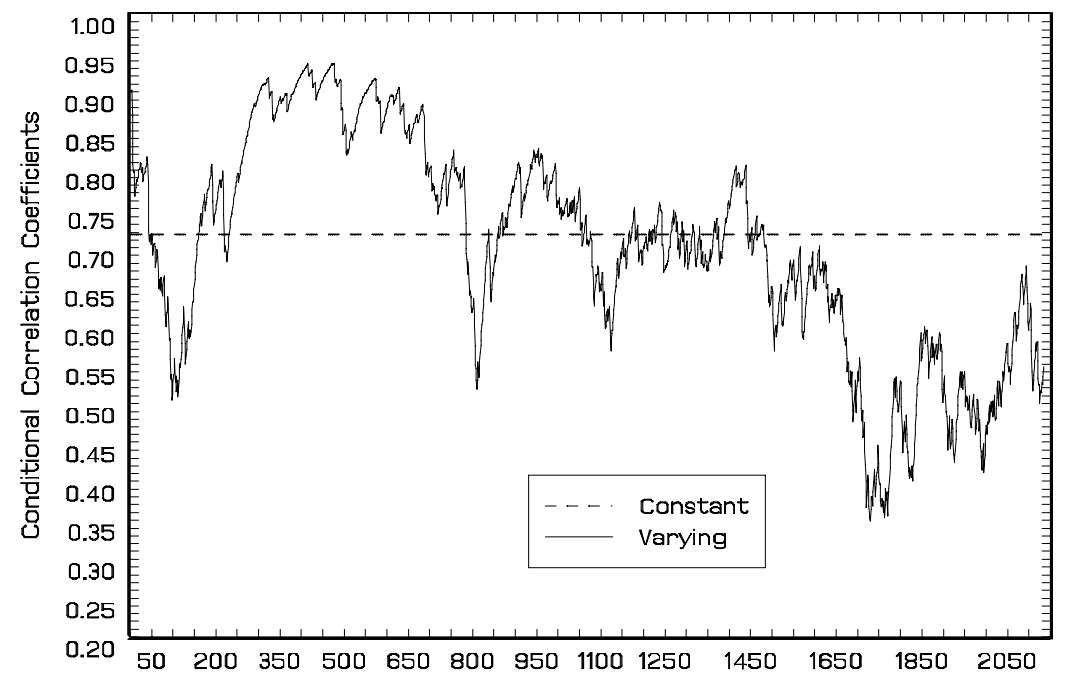

Time

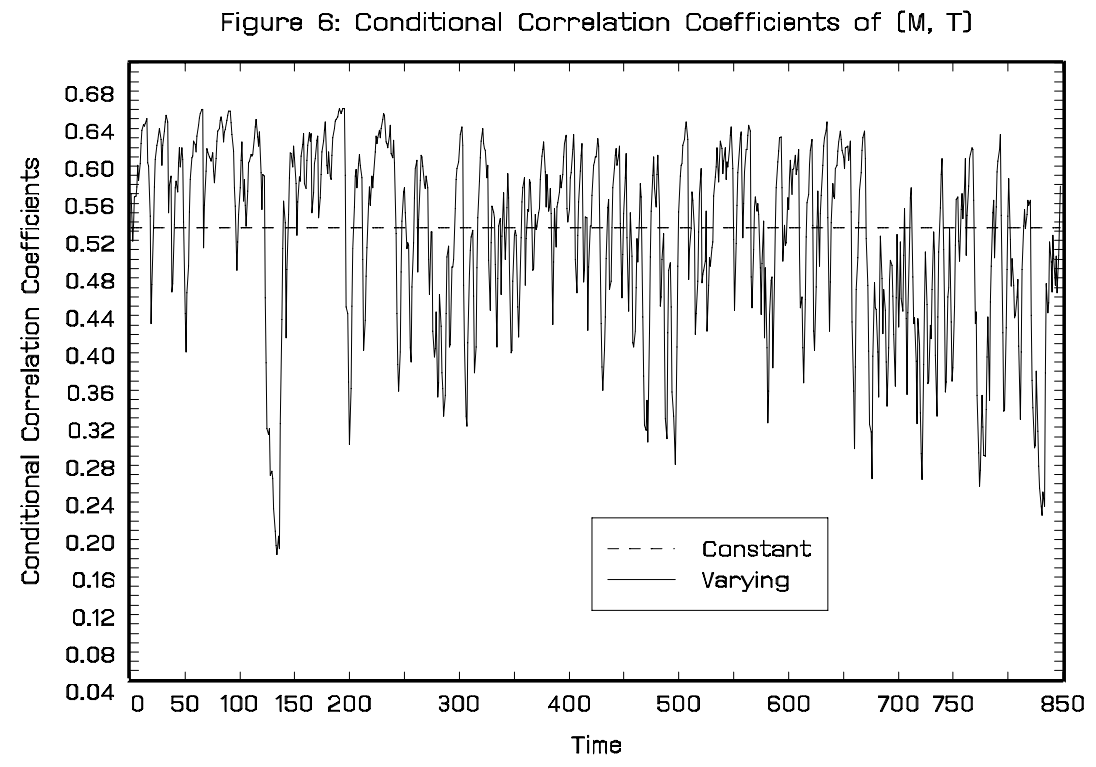

Figure 5: Conditional Correlation Coefficients of $[M, 0]$

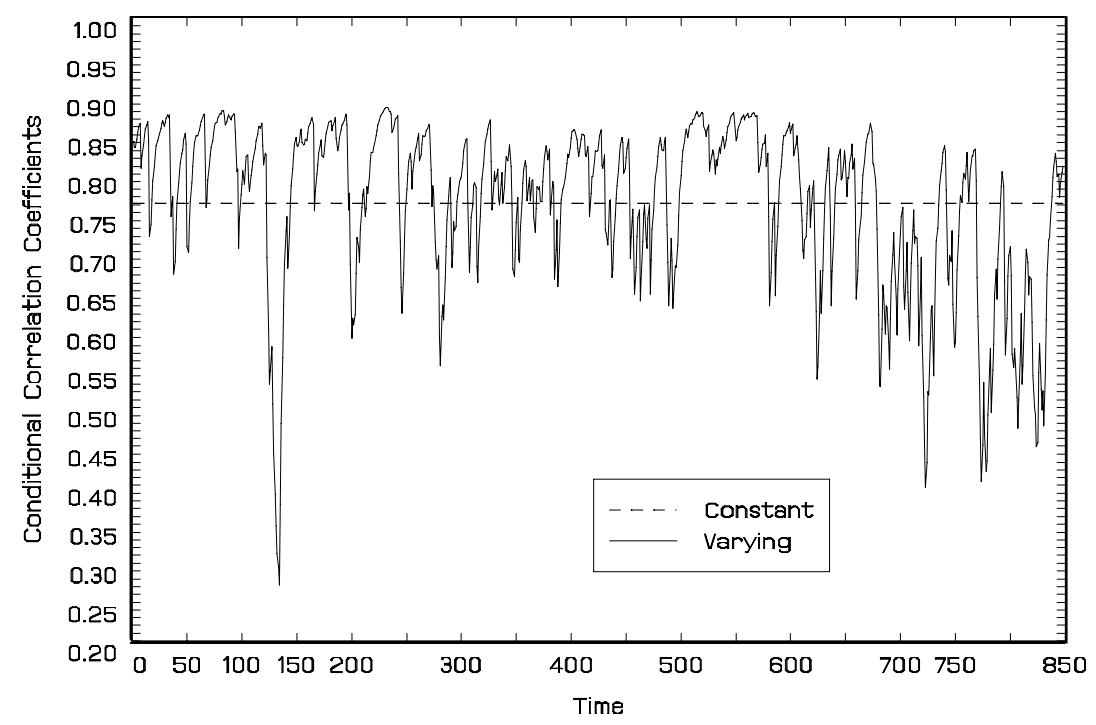

Figure 7: Conditional Correlation Coefficients of $[0, T]$

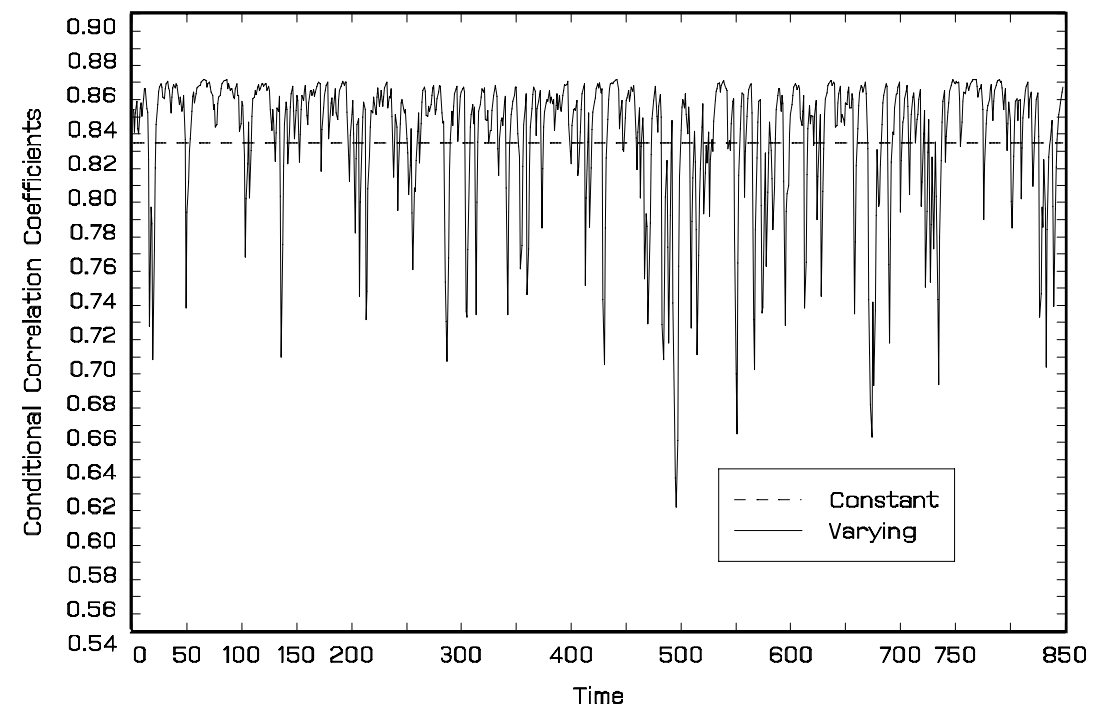


Figure 8: Conditional Correlation Coefficients of $[H, S]$

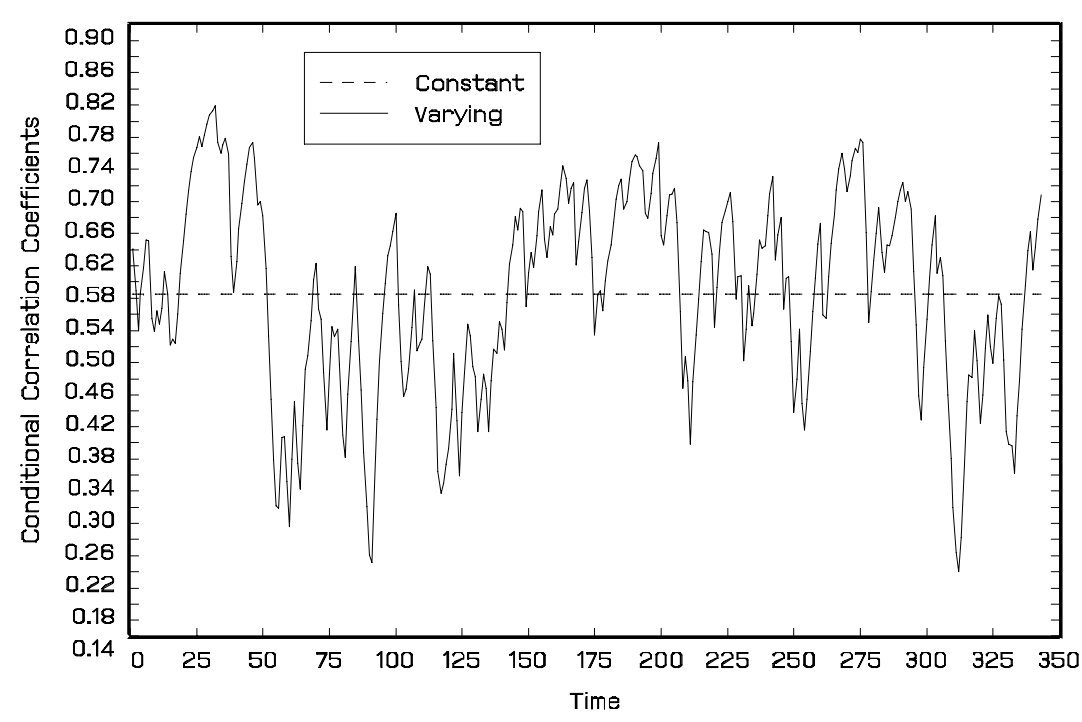

Figure 9: Conditional Correlation Coefficients of $[\mathrm{H}, \mathrm{J}]$

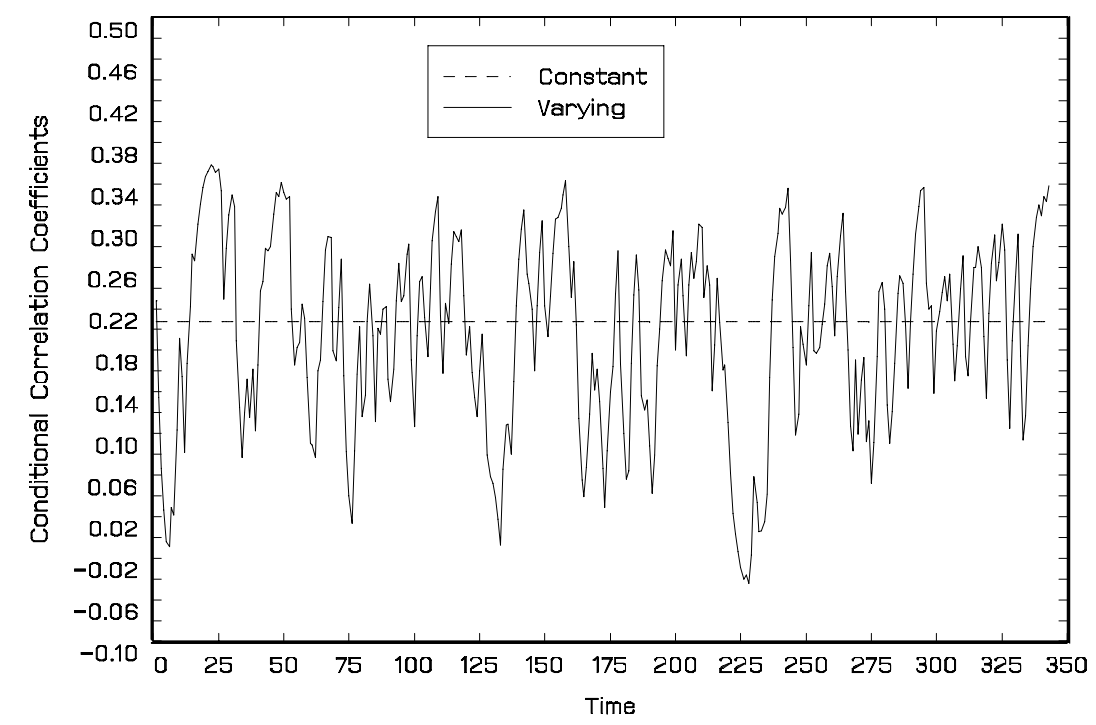

Figure 10: Conditional Correlation Coefficients of $[\mathrm{J}, \mathrm{S}]$

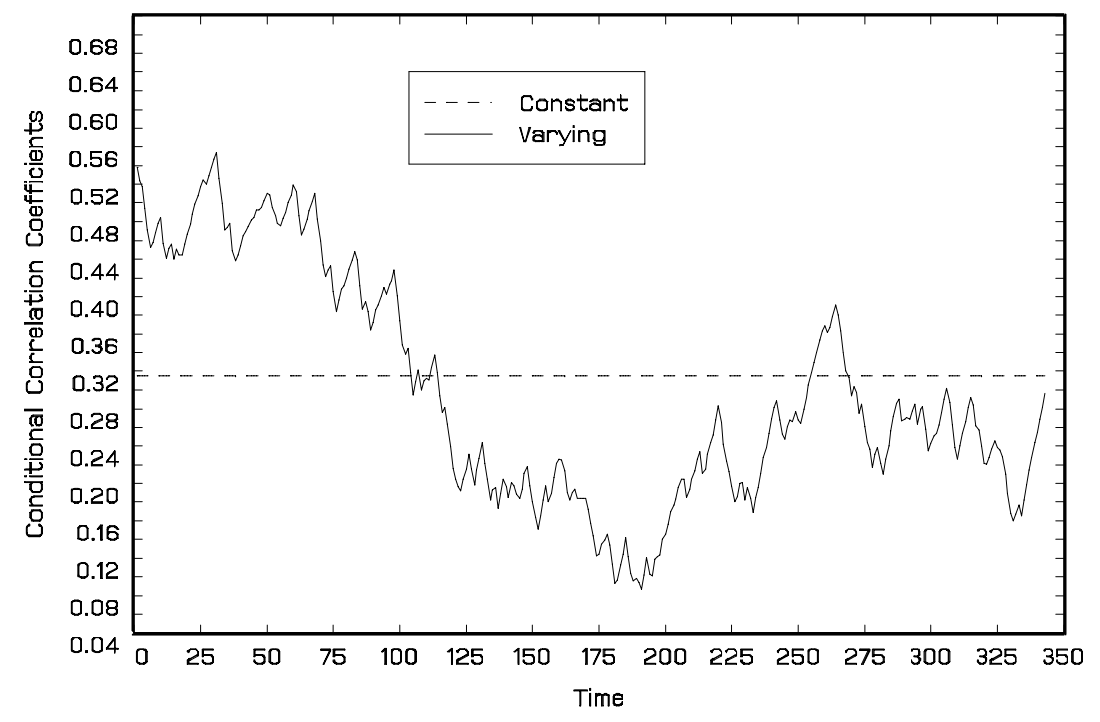

